\title{
A novel murine infection model for Shiga toxin-producing Escherichia coli
}

\author{
Emily M. Mallick, ${ }^{1}$ Megan E. McBee, ${ }^{2}$ Vijay K. Vanguri, ${ }^{3}$ Angela R. Melton-Celsa, ${ }^{4}$ \\ Katherine Schlieper, ${ }^{2,5}$ Brad J. Karalius, ${ }^{6}$ Alison D. O'Brien, ${ }^{4}$ \\ Joan R. Butterton, ${ }^{6}$ John M. Leong, ${ }^{1,7}$ and David B. Schauer ${ }^{2,5}$
}

\begin{abstract}
1Department of Microbiology and Physiological Systems, University of Massachusetts Medical School, Worcester, Massachusetts, USA. 2Department of Biological Engineering, Massachusetts Institute of Technology, Cambridge, Massachusetts, USA. ${ }^{3}$ Department of Pathology, University of Massachusetts Medical School, Worcester, Massachusetts, USA. ${ }^{4}$ Department of Microbiology and Immunology,

Uniformed Services University of Health Sciences, Bethesda, Maryland, USA. ${ }^{5}$ Division of Comparative Medicine, Massachusetts Institute of Technology, Cambridge, Massachusetts, USA. ${ }^{6}$ nfectious Disease Division, Department of Medicine, Massachusetts General Hospital, Boston, Massachusetts, USA. ${ }^{7}$ Department of Molecular Biology and Microbiology, Tufts University School of Medicine, Boston, Massachusetts, USA.
\end{abstract}

\begin{abstract}
Enterohemorrhagic E. coli (EHEC) is an important subset of Shiga toxin-producing (Stx-producing) E. coli (STEC), pathogens that have been implicated in outbreaks of food-borne illness and can cause intestinal and systemic disease, including severe renal damage. Upon attachment to intestinal epithelium, EHEC generates "attaching and effacing" (AE) lesions characterized by intimate attachment and actin rearrangement upon host cell binding. Stx produced in the gut transverses the intestinal epithelium, causing vascular damage that leads to systemic disease. Models of EHEC infection in conventional mice do not manifest key features of disease, such as $\mathrm{AE}$ lesions, intestinal damage, and systemic illness. In order to develop an infection model that better reflects the pathogenesis of this subset of STEC, we constructed an Stx-producing strain of Citrobacter rodentium, a murine AE pathogen that otherwise lacks Stx. Mice infected with Stx-producing C. rodentium developed AE lesions on the intestinal epithelium and Stx-dependent intestinal inflammatory damage. Further, the mice experienced lethal infection characterized by histopathological and functional kidney damage. The development of a murine model that encompasses $\mathrm{AE}$ lesion formation and $\mathrm{Stx}$-mediated tissue damage will provide a new platform upon which to identify EHEC alterations of host epithelium that contribute to systemic disease.
\end{abstract}

\section{Introduction}

Shiga toxin (Stx) is a potent phage-encoded cytotoxin, and Stxproducing Escherichia coli (STEC) have been implicated in serious outbreaks of food-borne disease. For example, an E. coli serotype O104 strain lysogenized with an Stx phage was responsible for a recent large outbreak of diarrheal illness with serious and in some instances lethal systemic complications (1). Enterohemorrhagic E. coli (EHEC) represent a subset of STEC, and EHEC, particularly serotype O157:H7, have been responsible for both sporadic cases and epidemic outbreaks of diarrheal illness in the United States as well as worldwide $(2,3)$. Human EHEC infection can cause severe local disease, such as hemorrhagic colitis, characterized by damage to the intestinal epithelium, acute abdominal pain, and bloody diarrhea (4-7). EHEC infection may also result in life-threatening systemic disease, most notably hemolytic uremic syndrome (HUS), characterized by the triad of hemolytic anemia, thrombocytopenia, and renal failure $(6,8)$. In fact, HUS is the leading cause of renal failure in children $(9,10)$.

A characteristic pathogenic feature of EHEC - one that it shares with enteropathogenic E. coli (EPEC), a cause of infantile diarrhea in the developing world, and Citrobacter rodentium, a natural murine pathogen - is the ability to generate attaching and effacing (AE) lesions $(2,11)$. These histopathological lesions are characterized by intimate adherence of the bacterium to the host cell, effacement of brush border microvilli, and the formation of filamentous actinrich pedestals beneath bound bacteria (ref. 12; for review, see ref. 2).

Authorship note: David Schauer is deceased.

Conflict of interest: The authors have declared that no conflict of interest exists.

Citation for this article: J Clin Invest. 2012;122(11):4012-4024. doi:10.1172/JCI62746.
The formation of AE lesions requires translocation of effector proteins into the mammalian cell via a type III secretion system $(13,14)$. A critical type III effector protein is Tir, which localizes in the host plasma membrane and acts as a receptor for the bacterial outer membrane protein intimin, promoting intimate adherence and filamentous actin assembly beneath bound bacteria (15-19). Both Tir and intimin are essential for colonization and virulence in several animal models of EHEC and Citrobacter infection (20-25).

Of the three AE pathogens, only EHEC produces Stx, which is largely responsible for the extensive tissue damage and systemic disease generated by EHEC $(6,26,27)$. Given that Stx is encoded by lambdoid prophages, its production is often enhanced upon phage induction (28-30). Stx traverses the intestinal epithelium and targets the endothelium, leading to vascular damage, particularly in the kidney and CNS, tissues that express high levels of the Stx receptor and the glycolipid globotriaosylceramide, or $\mathrm{Gb}_{3}(31-33)$. Once inside eukaryotic cells, Stx inhibits protein synthesis by inactivating ribosomes. The action of Stx on endothelial cells leads to the induction of proinflammatory cytokines, thrombus formation in the vasculature, and renal damage (34-38). Stx1 and Stx2 are the two major serotypes of Stx, and EHEC that express exclusively Stx2 are associated with a greater risk of HUS (39-41). There are several variants of Stx2, of which Stx2c and Stx2dact are particularly important in human disease (42-44). In particular, Stx2dact is proteolytically activated in the intestinal mucus and is associated with STEC that cause toxigenic illness in humans despite the fact that they lack the ability to generate AE lesions $(45,46)$.

Injection of Stx into mice results in the induction of proinflammatory cytokines, vascular damage, hemolysis, and renal damage (47-50), but in contrast to piglet and rabbit infection models $(23,51-53)$, 


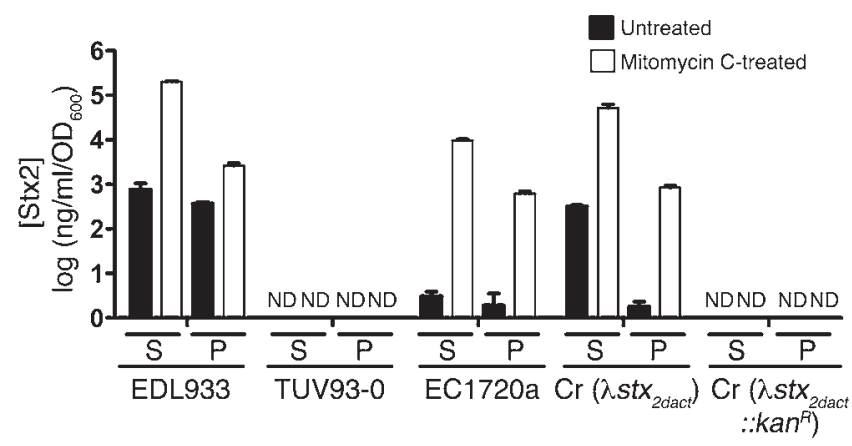

Figure 1

C. rodentium $\left(\lambda s t x_{2 d a c t}\right)$ produces high levels of Shiga toxin upon prophage induction at levels comparable to EHEC isolates. Stx2 in supernatants $(\mathrm{S})$ or pellets $(\mathrm{P})$ of untreated or mitomycin $\mathrm{C}$-treated cultures of the indicated strains was measured by capture ELISA, and results are expressed relative to bacterial number (see Methods). ND, not detected. Cr, C. rodentium. Data shown are the averages \pm SEM of quadruplicate samples. Data show results of 1 experiment representative of 3 independent experiments.

murine oral EHEC infection models do not recapitulate AE lesion formation, extensive mucosal colonization, or intestinal damage (54-56). For example, in conventional mice, Stx-mediated mortality occurs only after administration of large numbers of EHEC, numbers that diminish in the days following inoculation $(55,56)$. Disruption of the normal flora by antibiotic pretreatment, or its complete elimination by rearing of the animals in a germ-free environment, sensitizes mice to lethal infection after relatively lowdose oral inoculation (57-59). However, only STEC that produce the mucus-activatable allele Stx2dact consistently cause lethal infection of streptomycin-pretreated mice $(58,59)$. Furthermore, EHEC infection of altered-flora mice does not result in well-documented $\mathrm{AE}$ lesions, nor have bacterial genes that promote $\mathrm{AE}$ lesion formation been demonstrated to be required for intestinal colonization or disease (57-61). Indeed, a laboratory E. coli K12 strain that overproduces Stx 2 but lacks Tir, intimin, and the type III secretion apparatus is capable of lethal infection of streptomycin-pretreated mice (61).

The AE pathogen Citrobacter rodentium has been used extensively as a murine model for EHEC and EPEC colonization (20, 62-65) but does not express Stx. To establish an infection model that reflects both the characteristic mode of intestinal colonization and Stx-mediated disease, we constructed a C. rodentium strain lysogenized by an Stx2dact-producing phage. Administration of C. rodentium $\left(\lambda\right.$ stx $\left._{2 \text { dact }}\right)$ to mice by oral gavage recapitulated Tirdependent $\mathrm{AE}$ lesion formation, as well as important aspects of systemic Stx-mediated disease, such as intestinal and renal damage. Thus, C. rodentium ( $\lambda_{s t x_{2 d a c t}}$ ) provides a model for EHEC colonization and toxin-mediated disease in conventional mice.

\section{Results}

Cultured $C$. rodentium ( $\lambda$ stx $\left.x_{2 d a c t}\right)$, a C. rodentium strain lysogenized with a $\lambda$ Stx phage, produces mucus-activatable Stx2dact at levels comparable to STEC. In order to develop a murine model of Stx-mediated disease using $C$. rodentium, we generated C. rodentium strains expressing Stx1 or any of several alleles of Stx2, as well as Stx1/Stx2 hybrids (data not shown; see Methods). Two phages, $\Phi 1720 \mathrm{a}-02$ and the previously identified $\Phi 1720$ a-01, were derived from EC1720a, a
STEC strain originally isolated from ground beef (66). In preliminary screening of these $C$. rodentium lysogens, only C. rodentium ( $\Phi 1720 \mathrm{a}-02)$ produced significant amounts of toxin in vitro or caused systemic disease in mice (data not shown; see Figure 1). In order to facilitate the generation of lysogens of $\Phi 1720 \mathrm{a}-02$, the phage was marked with a chloramphenicol resistance cassette (cat, $\mathrm{Cm}^{\mathrm{R}}$ ) (see Methods). C. rodentium DBS100 (11) (referred to herein as C. rodentium) was lysogenized with $\Phi 1720 \mathrm{a}-02 R z::$ cat to create C. rodentium DBS770 ( $\Phi 1720 \mathrm{a}-02 R z:: c a t)$, which, for simplicity, we herein refer to as C. rodentium $\left(\lambda_{s t} x_{2 d a c t}\right)$. In addition, a C. rodentium

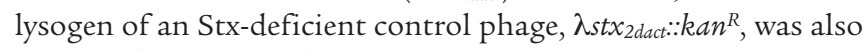
generated (see Methods).

To test whether C. rodentium ( $\left.\lambda_{s t x_{2 d a c t}}\right)$ was able to produce Stx2 upon in vitro growth, the level of Stx 2 was quantified by ELISA. Spontaneous prophage induction is predicted to release toxin into culture supernatants, so supernatants and bacterial pellets were analyzed separately. EDL933, an EHEC O157:H7 strain that harbors both $s t x_{1}$ and $s t x_{2}$ (67), produced high levels of Stx 2 in both the supernatant and pellet (Figure 1). In contrast, TUV93-0, the $s t x_{1}$ - and $s t x_{2}$-deficient derivative of EDL933 (68), was completely unable to produce Stx2. EC1720a, which harbors $\$ 1720 \mathrm{a}-01$ and $\Phi 1720 \mathrm{a}-02$, produced easily detectable levels of Stx 2 in both supernatant and pellet, albeit at levels several orders of magnitude lower than those found for EDL933, suggesting that baseline expression and/or prophage induction is lower in this strain. Importantly, C. rodentium $\left(\lambda s t x_{2 d a c t}\right)$ produced high levels of Stx 2 , the vast majority of which was present in the culture supernatant. As predicted, C. rodentium $\left(\lambda_{s t x_{2 d a c t}:: k a n^{R}}\right)$ did not produce detectable toxin.

Induction of the Stx-producing prophage often promotes high-level production of Stx by EHEC strains (28-30), so each of the above bacterial strains was treated with mitomycin $\mathrm{C}$ to induce lysogenic phage. Compared with uninduced samples, cultures of EDL933, EC1720a, and C. rodentium $\left(\lambda_{s t} x_{2 d a c t}\right)$ treated with mitomycin $C$ produced several orders of magnitude more Stx2, particularly in the supernatant, consistent with lytic induction of the stx-encoding prophage (Figure 1). Strain TV93-0 and C. rodentium $\left(\lambda_{s x_{2 d a c t}: k a n^{R}}\right)$ did not produce any Stx upon mitomycin C treatment, as predicted. Notably, the levels of Stx produced by C. rodentium ( $\lambda$ stx 2dact $_{\text {) }}$ ) were comparable to or higher than the levels generated by the EHEC strains EC1720a and EDL933, suggesting that this strain might produce Stx-mediated disease upon animal infection.

The sequences of $s t x A$ (Stx2d activatable A subunit) and $s t x B$ (Stx2d activatable B subunit) of $\Phi 1720 \mathrm{a}-02$ were determined, and although the inferred amino acid sequences aligned well with non-mucus-activatable Stx2d (69), the A subunit contained the C-terminal glutamic acid necessary for activation of Stx2dact (refs. 46, 58, and Supplemental Figure 1, A and B; supplemental material available online with this article; doi:10.1172/ JCI62746DS1). Thus, we tested the capacity of the toxin produced by C. rodentium ( $\left.\lambda_{s t} x_{2 \text { dact }}\right)$ to be activated in the presence of intestinal mucus. Strains B2F1, which encodes the mucus-activatable toxin Stx2dact, and EH250, which encodes the non-activatable Stx $2 \mathrm{~d}$, were used as positive and negative controls, respectively $(46,69,70)$. Culture supernatants from each strain were incubated with murine intestinal mucus or with buffer alone, and the Vero cell cytotoxicity of serially diluted samples was determined. Toxin activity in culture supernatants from E. coli strain B2F1 increased approximately 15-fold upon incubation with murine mucus (Table 1). In contrast, the toxin activity of EH250, 
Table 1

Stx2d from $C$. rodentium ( $\lambda s t x_{2 d a c t}$ ) is mucus activatable

\begin{tabular}{lccc}
\hline Strain & Fold activation & Range & $\boldsymbol{n}$ \\
$\operatorname{Cr}\left(\lambda s t x_{2 \text { dact }}\right)$ & $17.9 \pm 5.3^{\mathrm{A}}$ & $5.4-31$ & 4 \\
$\mathrm{~B} 2 \mathrm{~F} 1$ & $15.2 \pm 2.9^{\mathrm{A}}$ & $11.7-21$ & 3 \\
EH250 & $1.2 \pm 0.1$ & $1.1-1.3$ & 2 \\
\hline
\end{tabular}

Supernatant from C. rodentium ( $\lambda$ st $_{2 \text { dact }}$ ), B2F1 (as a positive control), and EH250 (as a negative control) were tested for Vero cell cytotoxicity in the presence or absence of mouse intestinal mucus. Shown is the average fold increase in cytotoxicity $( \pm S E M)$ with the addition of mouse intestinal mucus compared with supernatants incubated with buffer alone. $n$ represents the number of replicates performed for each strain tested. Statistical significance was determined using 1-way ANOVA. AP $<0.05$ compared with the increase in activation of EH250 in the presence of intestinal mucus.

which does not contain mucus-activatable toxin, increased only minimally in the presence of the mucus (Table 1 ). Toxin activity in the culture supernatant of C. rodentium $\left(\lambda_{s t x_{2 d a c t}}\right)$ increased approximately 18 -fold, comparable to the activity of E. coli B2F1, upon incubation with mucus, indicating that the Stx produced by $\lambda$ st $x_{2 \text { dact }}$ is indeed mucus activatable (Table 1 ).

C. rodentium $\left(\lambda_{s t} x_{2 d a c t}\right)$ causes lethal infection in mice. To determine whether C. rodentium ( $\left.\lambda_{s t x_{2 d a c t}}\right)$ would provide an Stx-mediated disease model, we infected 5- to 8-week old C57BL/6 mice with approximately $1 \times 10^{9} \mathrm{CFU}$ of this strain via oral gavage. As con-

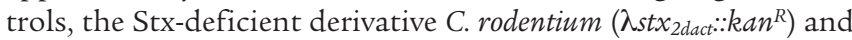
the parental nonlysogen C. rodentium DBS100 were inoculated in parallel. Fecal shedding of C. rodentium DBS100 and C. rodentium $\left(\lambda_{\left.s t x_{2 \text { dact }}:: k a n^{R}\right)}\right.$ reached approximately $3 \times 10^{9}$ to $5 \times 10^{9}$ per gram of feces at day 6 after infection and remained relatively constant to the end of monitoring, 10 days after infection (Figure 2A). C. rodentium $\left(\lambda_{s t} x_{2 d a c t}\right)$ colonized the feces with similar kinetics, reaching a peak of approximately $10^{10} \mathrm{CFU}$ per gram (Figure $\left.2 \mathrm{~A}\right)$.

To test whether mice infected with C. rodentium $\left(\lambda s t x_{2 d a c t}\right)$ experience Stx-mediated intestinal disease, we monitored fecal water content. As expected, feces from uninfected mice contained $45 \%-60 \%$ water throughout the course of infection (Figure $2 \mathrm{~B}$ ). Feces from mice infected with C. rodentium DBS100 or C. rodentium $\left(\lambda_{\left.s t x_{2 d a c t}:: k a n^{R}\right)}\right.$ had similar water content through day 4 after infection but starting at post-infection day 6 , a time point at which maximal bacterial burden was reached, contained elevated levels of water, as previously observed for non-Stx-producing C. rodentium (71). In contrast, water content of feces from mice infected with C. rodentium $\left(\lambda_{s t x_{2 d a c t}}\right)$ was significantly elevated (> $\left.70 \%\right)$ at 4 days after infection (Figure $2 \mathrm{~B}$ ), indicating that the production of Stx was associated with an early increase in fecal water content. By 8 days after infection, fecal water content declined to normal values, which could be due to the putative increasing dehydration and concomitant water reabsorption that may occur in these mice during later stages of infection (see Figure 2B).

Weight loss is a notable feature in mice after Stx injection or infection in mice with an intact commensal flora with high doses of STEC $(47,48,54)$. We found that mock-infected mice, as well as mice infected with C. rodentium DBS100 or C. rodentium $\left(\lambda_{s t} x_{2 d a c t}: k a n^{R}\right)$, maintained body weight throughout infection, indicating that infection with $C$. rodentium strains that do not produce Stx were not associated with weight loss (Figure $2 \mathrm{C}$ ). In contrast, mice infected with C. rodentium $\left(\lambda_{s t} x_{2 \text { dact }}\right)$ lost $>10 \%$ of their starting weight by 6 days after infection and $>20 \%$ by 8 days after infection.

Finally, the severe weight loss in mice infected with C. rodentium $\left(\lambda s t x_{2 d a c t}\right)$ corresponded temporally with mortality or severe disease warranting euthanasia (Figure 2D). All mock-infected mice or mice
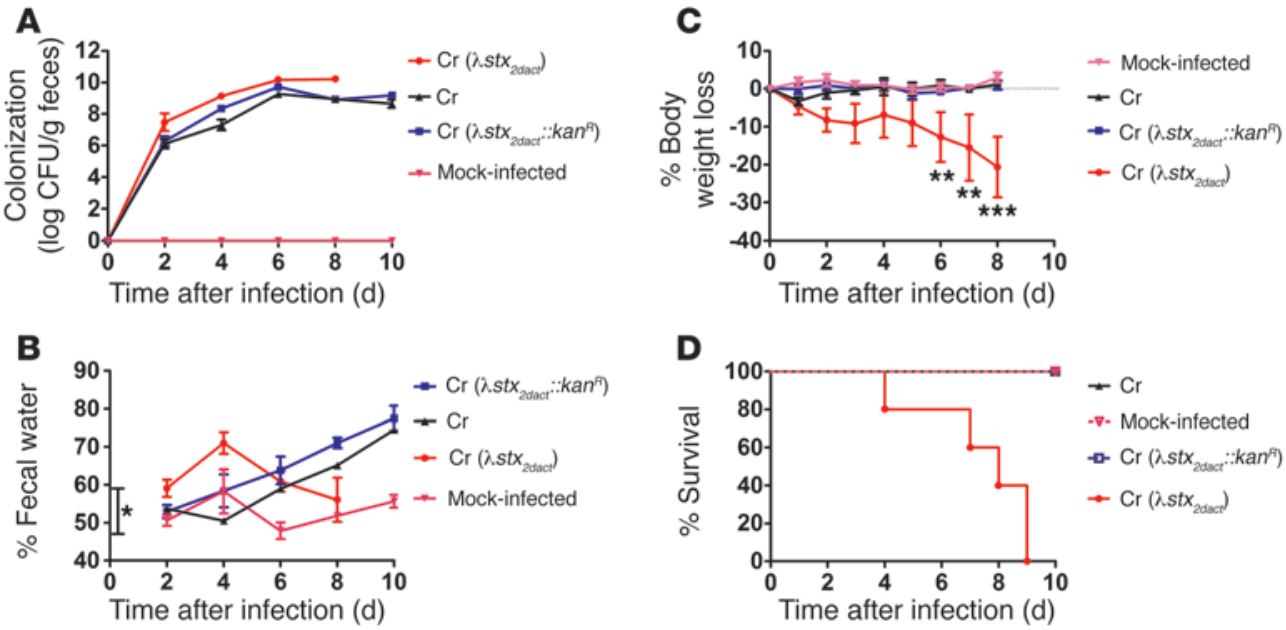

\section{Figure 2}

C. rodentium $\left(\lambda s t x_{2 d a c t}\right)$ causes lethal infection in mice. (A) Colonization of 5-week-old C57BL/6 mice by C. rodentium ( $\lambda$ stx 2 dact), C. rodentium $\left(\lambda\right.$ stx $\left._{2 \text { dact }}: . \mathrm{kan}^{R}\right)$, and C. rodentium (DBS100) was determined by viable stool counts. Shown are the average CFU $( \pm$ SEM) of 5 mice. (B) Fecal water content of mock-infected 5 -week-old mice or mice infected with C. rodentium $\left(\lambda s t x_{2 d a c t}\right)$, C. rodentium $\left(\lambda s t x_{2 d a c t}:\right.$ kan $\left.{ }^{R}\right)$, or C. rodentium (DBS100). Shown are the averages $( \pm$ SEM) of groups of 5 mice. Range of average fecal water content of uninfected mice is represented by the vertical bar at 0 days after infection. ${ }^{\star} P<0.05$ compared with all other groups as determined by 2-way ANOVA followed by Bonferroni post tests. (C) Body weight during infection of 8-week-old mice, expressed as percent change from day 0 . Shown are the averages ( \pm SEM) of 5 mice per group. ${ }^{* \star} P<0.01,{ }^{* \star} P<0.001$ compared with all other groups as determined by 2-way ANOVA followed by Bonferroni post tests. (D) Percent survival of groups of five 8 -week-old mice that were mock infected or infected with C. rodentium $\left(\lambda s t x_{2 d a c t}\right)$, C. rodentium $\left(\lambda s t x_{2 d a c t}:: k a n^{R}\right)$, or C. rodentium (DBS100). For all panels, results are representative of at least 5 independent experiments. 

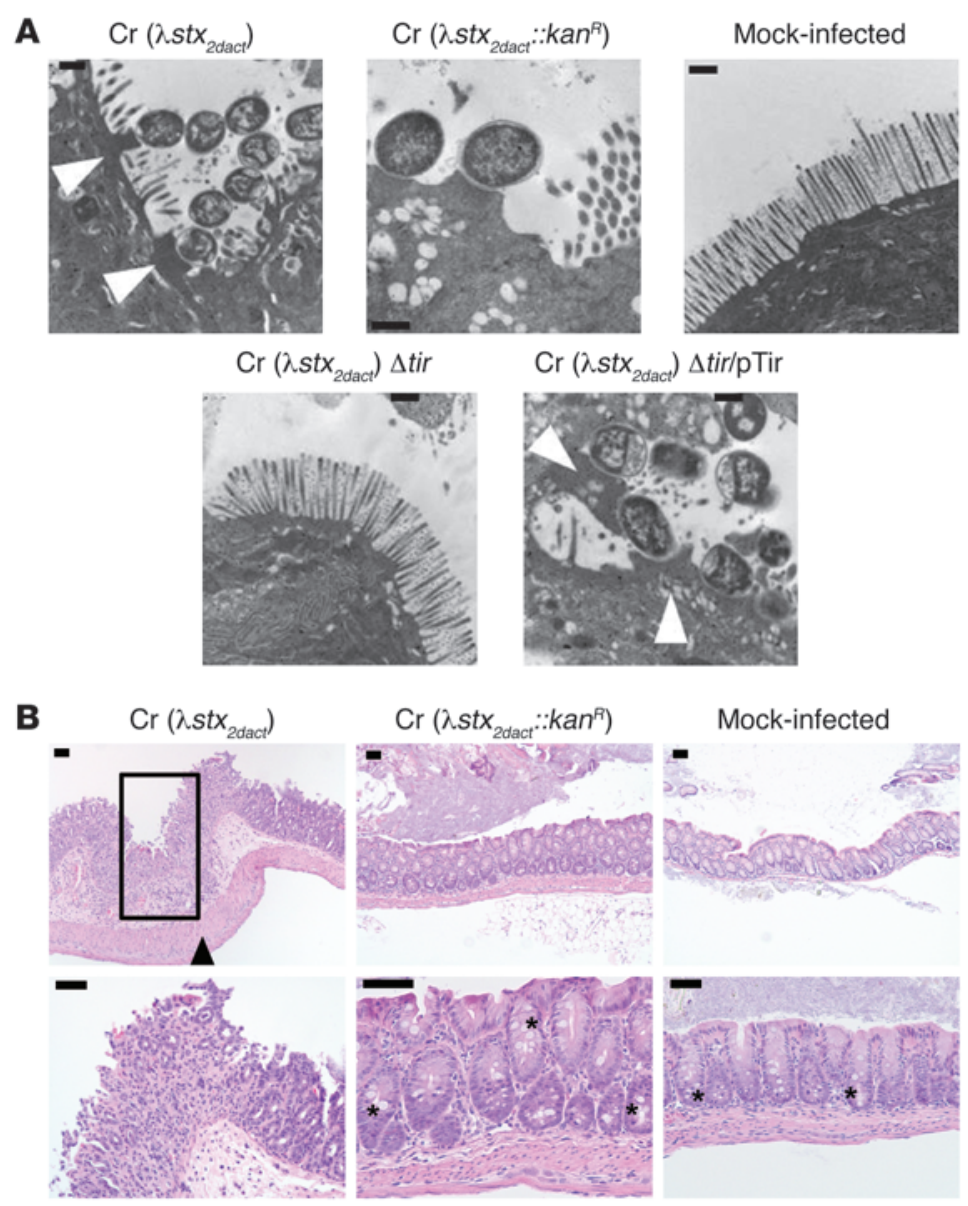

Figure 3

Stx-mediated intestinal damage during murine infection with $C$. rodentium $\left(\lambda s t x_{2 d a c t}\right)$. (A) TEM of the proximal large intestine of C57BL/6 mice 6 days after mock infection or infection by the indicated strain. White arrowheads indicate the presence of actin-rich pedestals. Scale bars: $0.5 \mu \mathrm{m}$. (B) H\&E-stained large intestinal section of mock-infected mice or mice infected with the designated strain 7 to 10 days after infection; original magnification, $\times 100$ (top row), $\times 200$ (bottom row, left and right panels), $\times 400$ (bottom row, middle panel). Scale bars: $50 \mu \mathrm{m}$. Black box indicates area of complete crypt loss and abscess formation. Asterisks indicate goblet cells that are prominent in normal intestinal tissue and diminished in mice infected with $C$. rodentium $\left(\lambda s t x_{2 d a c t}\right)$. Arrowhead indicates infiltration of inflammatory cells into the mucscularis mucosa and muscularis propria layers.

infected with C. rodentium DBS100 or C. rodentium $\left(\lambda_{s t} x_{2 \text { dact }}: k a n^{R}\right)$ survived. In contrast, mortality was observed in mice infected with C. rodentium $\left(\lambda s t x_{2 d a c t}\right)$ starting at day 4 after infection, and (in the experiment represented in Figure 2D) no mice survived past day 9. Consistent with the previous correlation between weight loss and serious systemic disease $(47,48,54)$, nearly all ( $95 \%)$ of mice that died or were euthanized had lost $>20 \%$ body weight at the preceding weight assessment (data not shown).

Stx-mediated intestinal damage during murine infection with C. rodentium $\left(\lambda s t x_{2 d a c t}\right)$. Although EHEC infection of humans is associated with hemorrhagic colitis, EHEC and/or STEC infection of streptomycinpretreated or gnotobiotic mice does not typically result in obvious AE lesion formation or striking intestinal damage (refs. 57, 59, and A. Melton-Celsa, unpublished observations). Efforts to document Stx-dependent hemorrhagic colitis using a guaiac fecal occult blood test were complicated by the fact that this nonquantitative assay also detected occult blood in the stool of mice infected with the non-Stx-producing C. rodentium $\left(\lambda_{\left.s t x_{2 d a c t}:: k a n^{R}\right)}\right.$ (Supplemental Figure 2).

To assess the presence of AE lesions in mice infected with C. rodentium $\left(\lambda s t x_{2 \text { dact }}\right)$, we examined colonic tissue by transmission electron microscopy (TEM) at 6 days after infection. Indeed, intimate bacterial attachment, microvillar effacement, and robust actin pedestals were produced on the intestinal epithelium of mice infected with C. rodentium $\left(\lambda s t x_{2 d a c t}\right)$, in contrast to the normal intestinal architecture observed in mock-infected mice (Figure 3A). As predicted from previous work (11), Stx was not required for the development of AE lesion formation, because mice infected with $C$. rodentium $\left(\lambda s t x_{2 \text { dact }}: k a n^{R}\right)$ developed distinct AE lesions beneath bound bacteria (Figure $3 \mathrm{~A}$ ).

To investigate intestinal disease caused by infection with C. rodentium $\left(\lambda_{s t} x_{2 d a c t}\right)$, the large intestines of mice infected with C. rodentium ( $\left.\lambda_{\text {st }} x_{2 \text { dact }}\right)$ for $7-10$ days were examined histologically. In accordance with previous studies, mice infected with C. rodentium DBS100 or C. rodentium $\left(\lambda s t x_{2 d a c t}: k a n^{R}\right)$ showed limited intestinal pathology, with only minimal hyperplasia and inflammatory infiltrates compared with mock-infected mice (data not shown and Figure 3B). (C. rodentium infection typically results in colonic hyperplasia only after approximately 14 days of infection [refs. 63, 72] and was not observed here). In contrast, gross evaluation of intestines from mice infected with C. rodentium $\left(\lambda s t x_{2 \text { dact }}\right)$ showed severe destruction of the intestinal mucosa, colitis, and acute ischemic injury, with neutrophil infiltration into the muscularis layer and lamina propria and intestinal abscesses (Figure 3B). Also present were areas of necrosis and degenerative changes in the epithelial cells, with crypt withering and an overall loss of goblet cells. These data show that C. rodentium $\left(\lambda_{s t} x_{2 \text { dact }}\right)$ infection is associated with $\mathrm{AE}$ lesion formation and severe Stx-mediated intestinal damage.

Stx-mediated systemic induction of proinflammatory cytokines during murine infection with C. rodentium ( $\lambda$ st $\left.x_{2 d a c t}\right)$. Although Stx is capable of activating complement (73-75), serum levels of complement proteins C3 and $\mathrm{Bb}$ in mice infected with $C$. rodentium $\left(\lambda_{s t} x_{2 d a c t}\right)$ were not altered, and sC5b-9 was elevated only transiently at

7 days after infection (data not shown; see Methods). Instead, in measuring 23 cytokines in the sera of mice infected with C. rodentium ( $\lambda_{\left.s t x_{2 d a c t}\right)}$ at $7-10$ days after infection (see Methods), we found that several proinflammatory cytokines and chemokines commonly associated with disease in humans and animal models of HUS $(47,48,50,76-78)$ were elevated relative to those in mock-infected mice and mice infected with $C$. rodentium

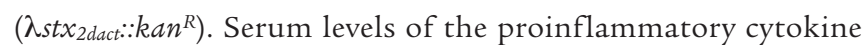
TNF- $\alpha$ were elevated, as were the neutrophil chemoattractants IL-17 and KC (Figure 4). Additionally, macrophage/monocyte chemoattractants RANTES, MCP- 1 , and MIP- $1 \beta$ were elevated 2 - to 5 -fold in serum from $C$. rodentium $\left(\lambda_{\text {stx }}\right.$ 2dact $)$-infected mice relative to mock-infected mice or mice infected with $C$. rodentium $\left(\lambda s t x_{2 d a c t}: k a n^{R}\right)$ (Figure 4). Thus, induction of the cytokines/chemokines was attributable to the production of Stx2dact rather than to simple colonization by C. rodentium. 

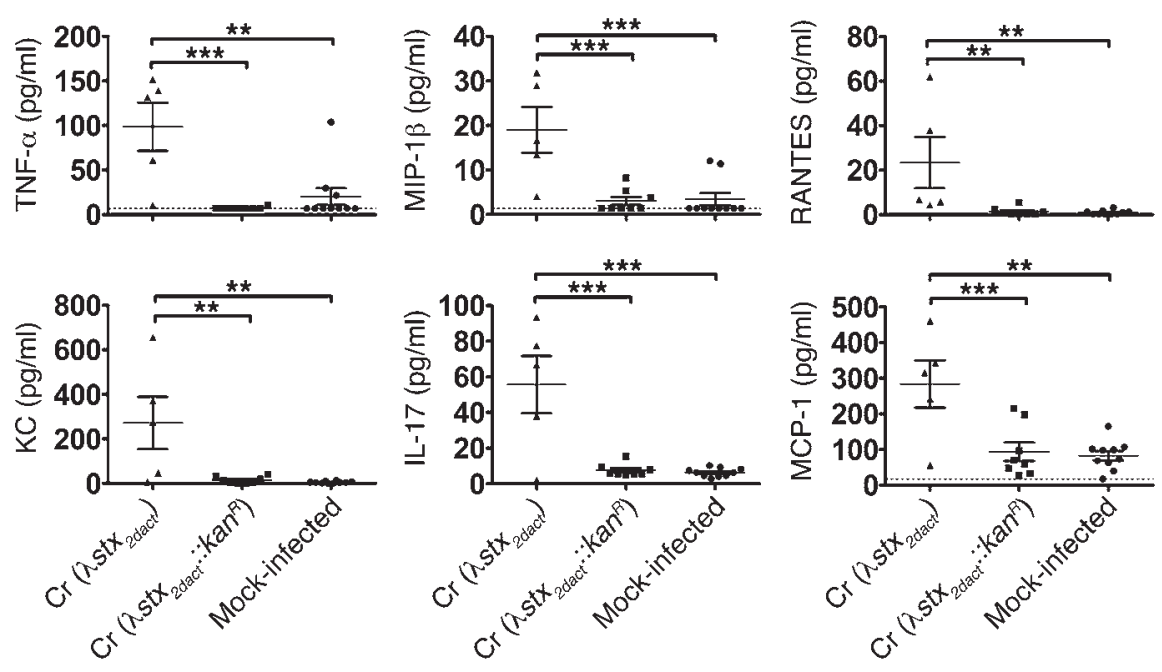

\section{Figure 4}

Stx-mediated systemic induction of proinflammatory cytokines during murine infection with C. rodentium $\left(\lambda s x_{2 d a c t}\right)$. The concentrations of TNF- $\alpha$, KC, MIP-1 $\beta$, IL-17, RANTES, and MCP-1 in serum at 7-10 days after infection in mock-infected mice or mice infected with the indicated strain were determined by Luminex (see Methods). Data are pooled from 2 independent experiments, each using 3- to 8-week-old female mice and 5-10 mice per group. ${ }^{* *} P<0.01,{ }^{* \star *} P<0.001,1$-way ANOVA and Tukey's multiple comparison tests.
The kidney is a specific target of Stx-mediated damage during murine infection with $C$. rodentium $\left(\lambda_{s t x_{2 d a c t}}\right)$. Although thrombocytopenia and hemolytic anemia are two prominent manifestations of HUS, the platelet and red blood cell blood counts of mice infected with C. rodentium $\left(\lambda_{s t} x_{2 d a c t}\right)$ were not significantly elevated relative to those of mock-infected mice or mice infected with $C$. rodentium $\left(\lambda_{\left.s t x_{2 d a c t}:: k a n^{R}\right)}\right.$ (data not shown; see Methods). Red blood cells were morphologically normal, and evidence of thrombotic microangiopathy, such as platelet aggregates, excessive clotting, or elevated levels of fibrin D-dimers, was not observed (data not shown).

We also histologically evaluated several extraintestinal tissues for damage upon intestinal infection by $C$. rodentium $\left(\lambda_{s t} x_{2 \text { dact }}\right)$. The lungs and heart of mice infected with C. rodentium $\left(\lambda_{s t} x_{2 d a c t}\right)$ revealed no pathology (Supplemental Figure 3, A and B). Nasal turbinates express $\mathrm{Gb}_{3}$ receptors (79) but appeared normal after C. rodentium $\left(\lambda_{s t} x_{2 d a c t}\right)$ infection (Supplemental Figure $\left.3 \mathrm{C}\right)$. Although the spleens of mice infected with C. rodentium $\left(\lambda_{s t} x_{2 d a c t}\right)$ showed reactive germinal center formation and germinal center hyperplasia with large follicles, mice infected with C. rodentium $\left(\lambda_{\left.s t x_{2 d a c t}:: k a n^{R}\right)}\right)$ also showed considerable germinal center activity (Supplemental Figure 3D). Finally, examination of the livers of mice infected with C. rodentium $\left(\lambda_{s t x_{2 d a c t}}\right)$ or C. rodentium $\left(\lambda s t x_{2 \text { dact }}: * k a n^{R}\right)$ revealed foci of neutrophilic and lymphocytic inflammation as well as scattered hepatocellular death (Supplemental Figure 3E). This injury in mice infected with C. rodentium $\left(\lambda_{s t} x_{2 d a c t}\right)$ was somewhat more severe than in mice infected with C. rodentium $\left(\lambda_{s t} x_{2 d a c t}: k a n^{R}\right)$, consistent with the elevation of serum proinflammatory cytokines. Consistent with the lack of thrombocytopenia, we found no platelet aggregates in any of the tissues (data not shown).

Kidney damage is a hallmark of HUS, and Stx causes renal pathology in mice after direct injection or upon absorption from intestinal STEC $(47,48,54,59)$. Renal cytokines and chemokines are elevated in murine models of Stx intoxication, so we measured cytokine and chemokine levels in the kidneys of mice infected with C. rodentium $\left(\lambda_{s t x_{2 d a c t}}\right)$ at $7-10$ days after infection. Although the levels of the cytokines IL- 6 and G-CSF varied considerably from mouse to mouse, they were significantly increased in the kidneys of mice infected with $C$. rodentium $\left(\lambda_{s t} x_{2 d a c t}\right)$ compared with mock-infected controls, as were the chemokines RANTES and KC (Figure 5A). In all cases, the increase in cytokine/chemokine levels was dependent on the production of Stx2dact, because infection by
C. rodentium $\left(\lambda_{s t x_{2 d a c t}: k a n^{R}}\right)$ was not associated with any significant elevation in levels (Figure 5A). Furthermore, the increase in renal IL-6 and RANTES was at least in part a reflection of increased transcription of the corresponding genes, because RT-PCR analysis of kidney mRNA revealed elevated levels of Il6 and Rantes mRNA relative to mock-infected mice or mice infected with by

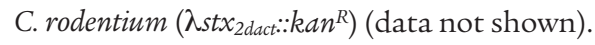

To evaluate renal pathology associated with the $C$. rodentium $\left(\lambda_{s t} x_{2 d a c t}\right)$ infection model, kidney sections were taken between 7 and 10 days after infection from mice infected with C. rodentium $\left(\lambda_{s t} x_{2 \text { dact }}\right)$ and were stained with H\&E and PAS. Although renal cytokines were elevated, infection with C. rodentium $\left(\lambda s t x_{2 \text { dact }}\right)$ was not associated with a striking renal inflammatory response (Figure $5 \mathrm{~B}$ and data not shown), nor was CCR1, a chemokine receptor associated with renal inflammation (80), elevated in the kidney (data not shown and see Methods). Instead, consistent with the observation that Stx intoxication of mice results in tubular damage (47-49), kidneys of mice infected with C. rodentium $\left(\lambda_{s t} x_{2 d a c t}\right)$ showed proximal tubule injury that was not evident in the kidneys of mockinfected mice or mice infected with C. rodentium $\left(\lambda s t x_{2 \text { dact }}: k a n^{R}\right)$ (Figure 5B). Their proximal tubular epithelium was flattened, with prominent pyknotic nuclear material, loss of luminal brush border, and sloughing of dead cells in the tubular lumen (Figure 5B, arrowheads). Mitotic activity, indicating regenerative repopulation of the proximal tubules, was also observed in some mice (data not shown).

To assess renal function in mice infected with C. rodentium $\left(\lambda_{s t} x_{2 d a c t}\right)$, we measured blood urea nitrogen (BUN) during the phase of terminal illness (7-10 days after infection) (see Methods). For each mouse euthanized due to severe disease prior to 10 days after infection, 1 mouse each from the mock-infected and C. roden-

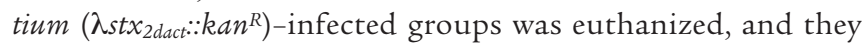
were analyzed in parallel. The mean BUN of mice infected with C. rodentium $\left(\lambda \lambda_{s t x_{2 d a c t}}\right)$ was significantly $(P<0.01)$ elevated relative to mock-infected mice, and was also elevated relative to mice

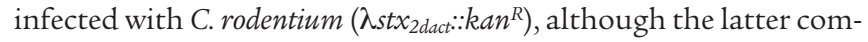
parison did not reach statistical significance (Figure $5 \mathrm{C}$ ).

Renal tubular damage, with both leakage of protein and sloughing of cells into the lumen, may result in proteinuria, hematuria, and elevated levels of the renal tubule-specific biomarker kidney injury molecule-1 (Kim-1) (refs. 81-83 and see Methods). Whereas urine of mock-infected mice or mice infected with C. rodentium 
A

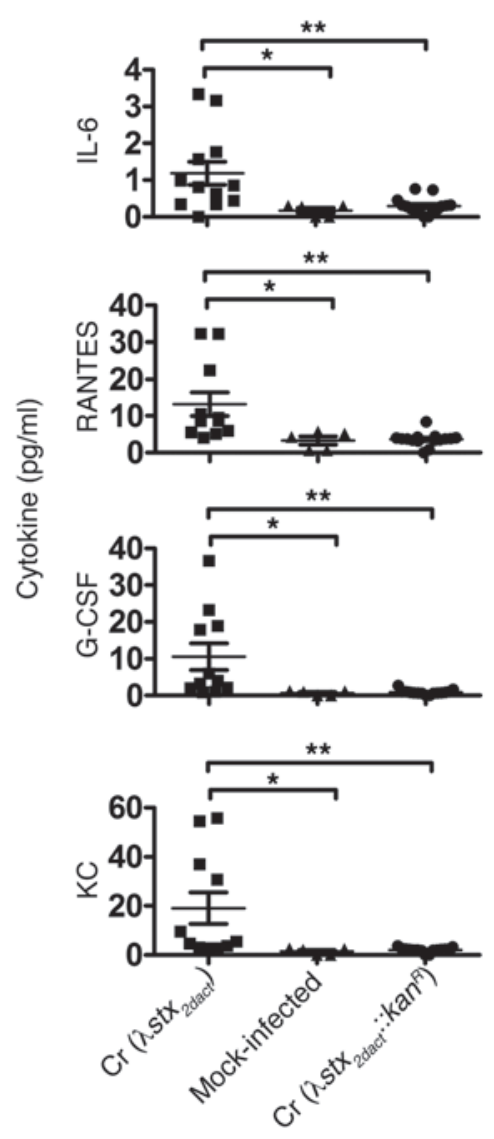

B

ป

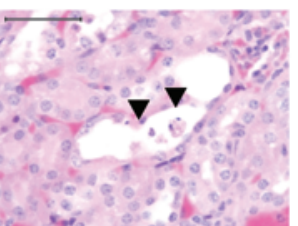

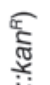
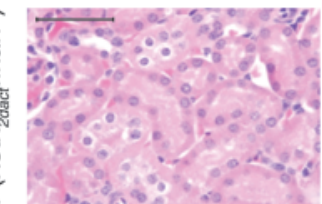

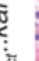

列

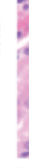

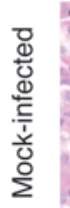

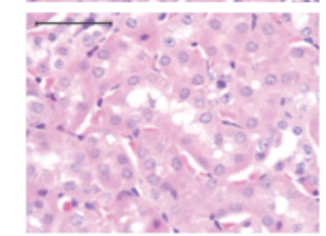

c.

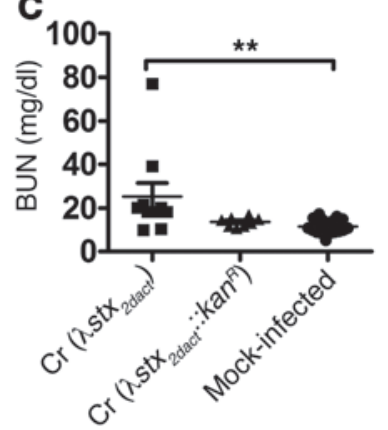

D
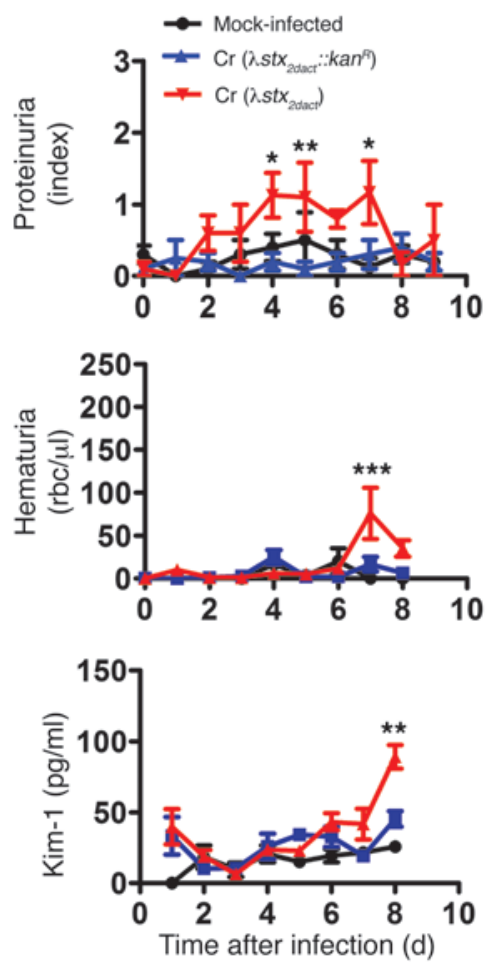

Figure 5

Stx-mediated renal damage during murine infection with $C$. rodentium $\left(\lambda s t x_{2 d a c t}\right)$. (A) Renal cytokines in mock-infected mice or mice infected with the indicated strain. Data are pooled from 3 independent experiments. ${ }^{*} P<0.05$, ${ }^{* *} P<0.01$. (B) Micrographs (original magnification, $\left.x 600\right)$ of H\&E-stained kidney sections from mock-infected mice or the indicated infected mice infected at 7-10 days after infection. Arrowheads indicate attenuation and sloughing of epithelial cells within the proximal tubules. Scale bars: $50 \mu \mathrm{m}$. (C) BUN of 8-week-old mice, each represented as a single data point, infected with indicated strain or mock infected at day of necropsy (7-10 days after infection). Shown is the pool of 4 independent experiments using 5 mice per group. ${ }^{* *} P<0.01$. (D) Proteinuria in mock-infected mice or the indicated infected mice. Data shown are average protein indices \pm SEM of 5 mice per group. The range of protein measured was $0-500 \mathrm{mg} / \mathrm{dl}$, with 0 indicating undetectable protein, $0.5 \mathrm{indicating}$ trace, 1.0 indicating $\sim 30 \mathrm{mg} / \mathrm{dl}, 2.0$ indicating $\sim 100 \mathrm{mg} / \mathrm{dl}$, and 3.0 indicating $\sim 500 \mathrm{mg} / \mathrm{dl}$. Shown is a representative of 5 independent experiments. ${ }^{*} P<0.05,{ }^{* *} P<0.01$ compared with $C$. rodentium $\left(\lambda s t x_{2 d a c t}: . k^{*} n^{R}\right)$. Hematuria in mock-infected mice or the indicated infected mice infected. Shown are the averages $\left( \pm\right.$ SEM) of groups of 10 mice. ${ }^{* \star \star} P<0.001$ compared with the other groups. Urine Kim- 1 concentration in mock-infected mice or the indicated infected mice. Shown are the averages $\left( \pm\right.$ SEM) of groups of 3-6 mice. ${ }^{\star \star} P<0.01$ compared with the other groups.

$\left(\lambda s_{2 t} 2\right.$ dact: $\left.: k a n^{R}\right)$ contained no or only trace levels of protein (protein index of $0-0.5$ indicating $<30 \mathrm{mg} / \mathrm{dl}$ ), urine of mice infected with C. rodentium $\left(\lambda_{s t} x_{2 \text { dact }}\right)$ contained significantly elevated protein indices as early as 2 days after infection (Figure 5D). Between 4 and 7 days after infection, average urine protein indices of the colorimetric assay were as high 1 to 1.5 , corresponding to approximately $30-100 \mathrm{mg} / \mathrm{dl}$. Hematuria, also assessed using a colorimetric assay, was moderately elevated on days 7 and 8 after infection. Finally, the marker for tubular damage Kim-1 was also elevated late in infection compared with mock-infected mice or mice infected with C. rodentium $\left(\lambda_{s t} x_{2 \text { dact }}: k a n^{R}\right)$. These results indicate that the tubular damage sustained during infection by $C$. rodentium $\left(\lambda_{s t x_{2 d a c t}}\right)$ reflected by histological analysis in fact results in functional renal compromise.

Tir is required for colonization and disease in the C. rodentium ( $\left.\lambda \boldsymbol{s t}_{2 \mathrm{dact}}\right)$ infection model. The ability to generate of AE lesions is a well-established virulence attribute of EHEC, but STEC strains that produce
Stx2dact are capable of causing disease in humans (and mice) in the absence of AE lesion formation $(45,58,59)$. To test whether murine infection with $C$. rodentium $\left(\lambda_{s t} x_{2 \text { dact }}\right)$ provided a disease model that was dependent on AE lesion formation, we determined whether a C. rodentium $\left(\lambda_{s t} x_{2 \text { dact }}\right)$ defective for Tir production was also defective for colonization and disease. Whereas $C$. rodentium $\left(\lambda_{s t} x_{2 d a c t}\right)$ and C. rodentium $\left(\lambda_{\left.s t x_{2 d a c t}: * k a n^{R}\right)}\right)$ were capable of generating actin pedestals indistinguishable from those formed by wildtype C. rodentium DBS100 on monolayers of mouse embryonic fibroblasts (MEFs), C. rodentium $\left(\lambda_{s t x_{2 d a c t}}\right) \Delta$ tir was impaired in cell binding and unable to form pedestals (data not shown). Pedestal formation was restored to this strain by pTir (pEM129), a Tirexpressing plasmid (data not shown; see Supplemental Table 2 and Methods). To confirm that Tir was also required for AE lesion formation during infection, we compared the intestinal epithelia

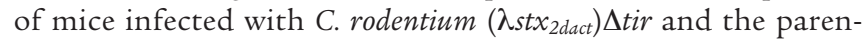


A
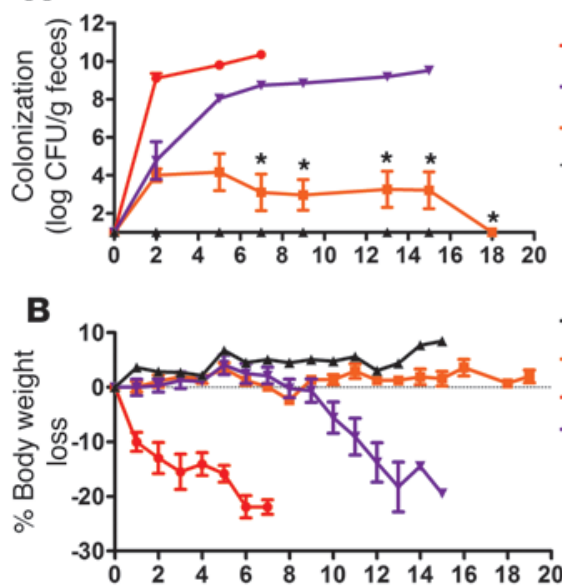

c
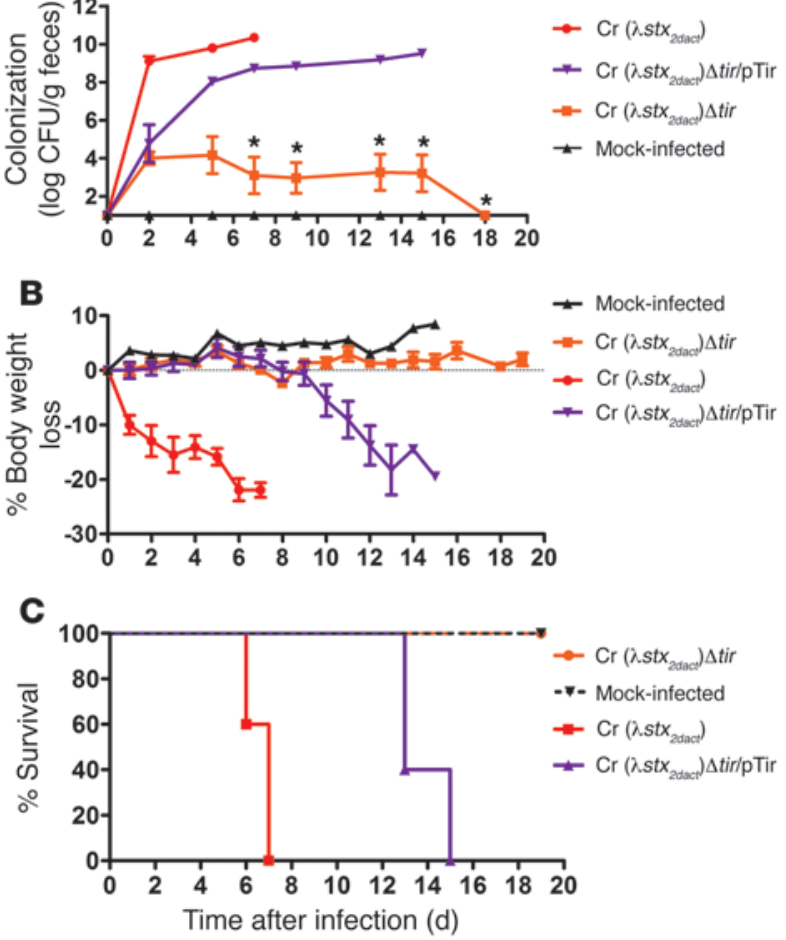

- Mock-infected

- $\operatorname{Cr}\left(\lambda s t x_{\text {2dace }}\right) \Delta t i r$

$\rightarrow \operatorname{Cr}\left(\lambda s t x_{2 a t a c}\right)$
D $\operatorname{Cr}\left(\lambda s t x_{2 \text { dact }}\right) \Delta t i r$

$\rightarrow \operatorname{Cr}\left(\lambda s t x_{\text {atacec }}\right) \Delta t i r / p T i r$
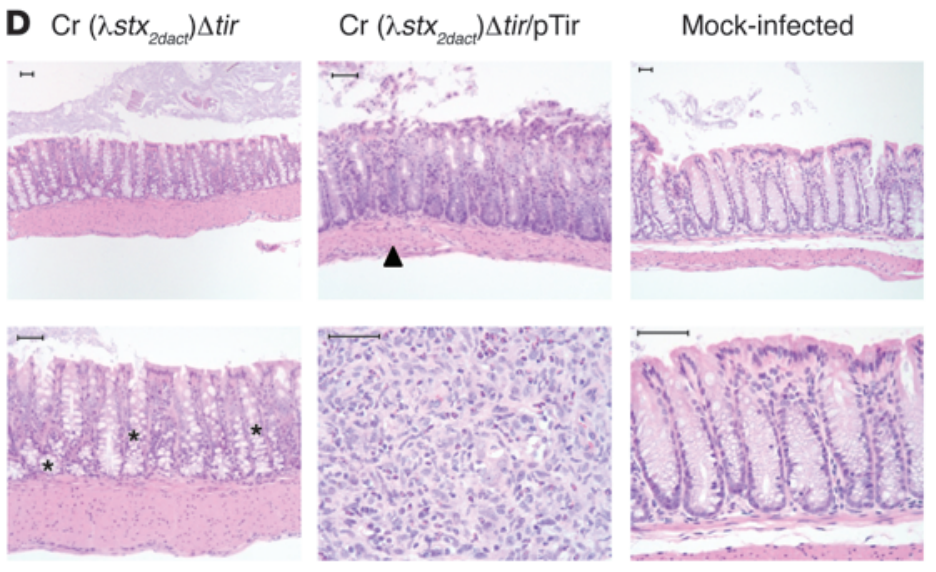

E

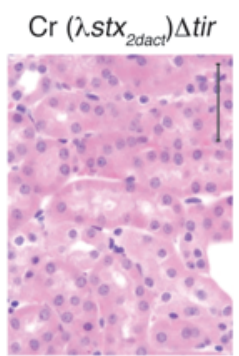

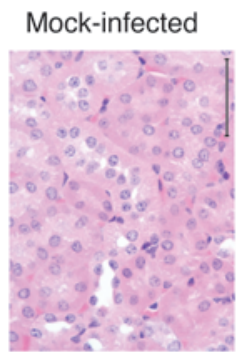

Figure 6

Tir is required for colonization and disease upon C. rodentium ( $\lambda$ st $\left.x_{2 d a c t}\right)$ infection of mice. (A) Colonization of 8-week-old C57BL/6 mice that were mock infected mice or infected with the indicated strain was determined by plating stool for viable counts. Shown are the averages CFU $( \pm$ SEM) of 5 mice. Data are representative of 5 independent experiments. Statistical significance was determined using 2-way ANOVA and Bonferroni post tests and indicates that $C$. rodentium $\left(\lambda s t x_{2 d a c t}\right) \Delta t i r$ colonized mice significantly $\left({ }^{*} P<0.05\right)$ less efficiently than $C$. rodentium $\left(\lambda s t x_{2 d a c t}\right)$ and C. rodentium ( $\left.\left.\lambda s t x_{2 d a c t}\right) \Delta t i r / p T i r\right)$. (B) Body weight during infection of 8-week-old mice is expressed as percent change from day 0 . Shown are the averages $( \pm S E M)$ of 5 mice per group. Data are representative of 5 independent experiments. (C) Percent survival of mock-infected 8 -week-old mice or mice infected with C. rodentium $\left(\lambda s t x_{2 d a c t}\right)$, C. rodentium $\left(\lambda s t x_{2 d a c t}\right) \Delta t i r$, or $C$. rodentium $\left(\lambda s t x_{2 d a c t}\right) \Delta t i r / p T i r$. Groups of 5 mice were analyzed. Data are representative of 5 independent experiments. (D) H\&E-stained large intestinal sections of mock-infected mice or mice infected with the indicated strain. Scale bars: $50 \mu \mathrm{m}$. Asterisks indicate goblet cells that are prominent in normal intestinal tissue. Arrowhead indicates infiltration of inflammatory cells into the mucscularis mucosa and muscularis propria layers. (E) H\&E-stained micrograph (original magnification, $\times 600$ ) of kidney sections from mock-infected mice or mice infected with the indicated strain. Arrowhead indicates attenuation and sloughing of epithelial cells within the proximal tubules. Scale bars: $50 \mu \mathrm{m}$.

tal strain C. rodentium $\left(\lambda_{\left.s t x_{2 d a c t}\right)}\right.$ by TEM at 6 days after infection. Whereas infection by $C$. rodentium $\left(\lambda_{\text {st }} x_{2 d a c t}\right)$ resulted in effacement of the intestinal brush-border microvilli and the formation of robust pedestals (Figure $3 \mathrm{~A})$, infection by C. rodentium $\left(\lambda_{s t} x_{2 d a c t}\right) \Delta$ tir left the epithelial cytoskeletal architecture indistinguishable from that of mock-infected controls. When tir was introduced in trans on pTir, the intestines of mice infected with C. rodentium $\left(\lambda_{s t} x_{2 d a c t}\right)$ $\Delta t i r / p$ Tir showed many bound bacteria elevated on actin pedestals (Figure 3B) with concomitant destruction of microvilli, indicating that, as expected, Tir is required for $\mathrm{AE}$ lesion formation.

The lack of mucosal attachment by C. rodentium $\left(\lambda_{s t x_{2 d a c t}}\right) \Delta t i r$ revealed by TEM reflected a significant colonization defect when assessed quantitatively, because mice infected with $C$. rodentium

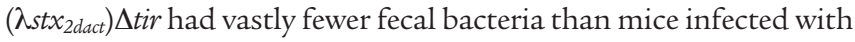
C. rodentium ( $\lambda_{s t x_{2 d a c t}}$ ) (Figure $\left.6 \mathrm{~A}\right)$. At 3 days after infection, fecal counts of mice infected with C. rodentium $\left(\lambda s t x_{2 d a c t}\right) \Delta t i r$ were approximately 3 orders of magnitude lower than those of mice infected with C. rodentium $\left(\lambda s t x_{2 \text { dact }}\right)$, and this difference grew to approximately 7 orders of magnitude 4 days later. In contrast, $C$. rodentium $\left(\lambda_{\left.s t x_{2 d a c t}\right) \Delta t i r / p T i r}\right.$ was capable of efficiently colonizing mice, with peak bacterial burdens reaching almost $10^{10}$ per gram of stool (Figure 6A). Notably, the kinetics of colonization by C. rodentium $\left(\lambda_{s t x_{2 d a c t}}\right) \Delta t i r / p$ Tir were somewhat delayed relative to $C$. rodentium $\left(\lambda s t x_{2 d a c t}\right)$, consistent with previous reports that plasmid complementation of a C. rodentium tir mutant is incomplete $(20,84)$.

The defect of C. rodentium $\left(\lambda_{s t} x_{2 \text { dact }}\right) \Delta$ tir in intestinal colonization was reflected in all aspects of Stx-mediated disease. Histological analyses of the intestines of mice infected with C. rodentium $\left(\lambda_{s t} x_{2 d a c t}\right)$ $\Delta$ tir were indistinguishable from those of mock-infected mice, in contrast to those of mice infected with C. rodentium $\left(\lambda s t x_{2 d a c t}\right)$ $\Delta t i r / p T i r$, which showed areas of necrosis, inflammatory infiltrates, and the loss of goblet cells (Figure 6D). Renal damage was associated only with infection by C. rodentium $\left(\lambda_{s t x_{2 d a c t}}\right) \Delta t i r / p T i r$, not with the Tir-deficient mutant (Figure 6E). These histological assessments of disease correlated with weight loss, because mice infected with $C$. rodentium $\left(\lambda s t x_{2 d a c t}\right) \Delta t i r$ maintained weight throughout infection (Figure $6 \mathrm{~B}$ ). In contrast, mice infected with

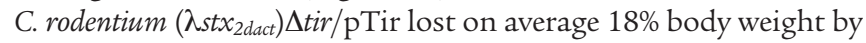
15 days after infection. The kinetics of weight loss by mice infected with the Tir-complemented strain, similar to the kinetics of colo- 
nization, were delayed several days relative to mice infected with C. rodentium $\left(\lambda_{s t} x_{2 \text { dact }}\right)$, but once average weight began to decrease at approximately 10 days post-infection, it declined steadily (Figure $6 \mathrm{~B}$ ). Finally, whereas infection by C. rodentium $\left(\lambda_{s t} x_{2 \text { dact }}\right) \Delta$ tir caused no mortality, infection by C. rodentium $\left(\lambda s t x_{2 \text { dact }}\right) \Delta t i r / p$ Tir, like C. roden-

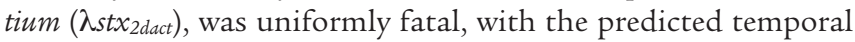
delay (Figure 6C). Thus, Tir is an essential virulence factor during lethal infection by C. rodentium $\left(\lambda_{s t x_{2 d a c t}}\right)$.

\section{Discussion}

STEC have been implicated in serious outbreaks of diarrheal disease and systemic damage, including a European outbreak due to a serotype O104 STEC strain (1). An important subclass of STEC is EHEC, which triggers the formation of AE lesions on the intestinal mucosa. Some rabbit and piglet models manifest both AE lesion formation and Stx-mediated disease $(21,23,52,53,85)$, but no such model has yet been developed in conventional mice. We show here that $C$. rodentium lysogenized with $\lambda$ Stx 2 dact, which produces a mucus-activatable Stx previously associated with severe disease in mice (59-61), provides a model that features prototypic AE lesions during intestinal colonization and Stx-mediated weight loss and death, recapitulating renal dysfunction observed in human HUS and murine toxin injection models $(4,54)$.

Systemic Stx-mediated disease in humans is associated with the induction of inflammatory cytokines $(77,86)$, and patients with a preponderance of proinflammatory cytokines often have more severe disease $(87,88)$. Indeed, one model of Stx-mediated disease in mice requires the co-administration of LPS and Stx (50). Several means by which inflammatory cytokines may promote systemic disease have been proposed, including induction of the $\mathrm{Gb}_{3}$ glycolipid Stx receptor on host cells (89-91), alteration of fibrinolysis and anticoagulation, or recruitment of inflammatory cells into damaged tissues (77). In response to Stx, cultured monocytes secrete TNF- $\alpha$ and IL- $6(90,92,93)$, and we found that these cytokines were elevated in the serum or kidneys of mice infected with C. rodentium $\left(\lambda_{s t} x_{2 d a c t}\right)$. This response was dependent on Stx production, because neither TNF- $\alpha$ nor IL- 6 was elevated in mice infected with C. roden-

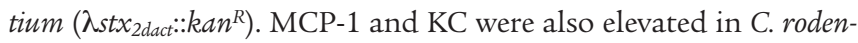
tium $\left(\lambda_{s t x_{2 d a c t}}\right)$-infected mice in an Stx-dependent manner. Notably, MCP-1 and IL-8, a functional human analog of KC, are found at elevated levels in the urine of children with HUS (94).

Renal damage is central to human HUS (9), and the induction of kidney cytokines in the C. rodentium $\left(\lambda_{s t} x_{2 d a c t}\right)$ model was accompanied by renal compromise. Glomerulonephritis is a prominent feature of human HUS, a manifestation that correlates with the relative abundance of $\mathrm{Gb}_{3}$ receptors on glomerular endothelium (95). In contrast, $\mathrm{Gb}_{3}$ is enriched in the renal tubules in mice (49), and the tubular damage we observed in infected mice likely reflects this localization. Consistent with this hypothesis, tubular damage is also typically observed in EHEC-infected germ-free or streptomycin-treated mice (49, 57-59). Elevated serum creatinine, an indicator of renal dysfunction, has been observed in some other murine models for Stx-mediated disease $(47,48,59)$, but we found that serum creatinine was not significantly elevated in mice infected with C. rodentium ( $\left.\lambda_{s t} x_{2 \text { dact }}\right)$ (E. Mallick, unpublished observations). A possible explanation is that elevated serum creatinine is a late marker of renal injury (82) and affected by many non-renal factors $(81,96)$. In fact, the renal histopathological findings were reflected in other measures of functional compromise, because mice infected with C. rodentium $\left(\lambda_{s t} x_{2 d a c t}\right)$, but not C. rodentium $\left(\lambda s t x_{2 d a c t}: k a n^{R}\right)$, demonstrated elevated BUN, proteinuria, hematuria, and urinary Kim-1, a marker of tubular damage, consistent with other murine models of HUS (47, 48, 54, 57, 59).

Several manifestations of murine Stx-mediated disease and human HUS are absent in the C. rodentium $\left(\lambda s t x_{2 d a c t}\right)$ murine model. For example, neurological damage is associated with HUS, and cerebral hemorrhage and edema have been reported in EHECinfected, streptomycin-pretreated mice $(97,98)$. Although mice infected with C. rodentium ( $\left.\lambda s t x_{2 d a c t}\right)$ occasionally displayed tremors and seizures, we did not observe consistent pathological changes in the nasal turbinates, a region of the CNS rich in the Stx receptor (79). In addition, contrary to what has been observed in human disease $(6,8)$ and Stx administration models (47-49, 88, 99-101), mice infected with $C$. rodentium $\left(\lambda_{s t x_{2 d a c t}}\right)$ did not display renal platelet aggregation, red cell congestion, or fibrin deposition and did not show evidence of thrombocytopenia or anemia. Given the hypothesis that erythrocytes are ruptured upon passage through damaged renal glomeruli (102), it is possible that the lack of glomerulonephritis in our model contributes to the lack of observable anemia. We also found no hematological evidence of thrombotic disease, such as prolonged clotting time or fibrin D-dimer formation. Following systemic administration of Stx, mice that are deficient in ADAMTS13, a protease that cleaves the hemostatic von Willebrand factor, demonstrate wide strain-specific variation in the degree of microvascular thrombosis, thrombocytopenia, and hemolytic anemia $(88,101)$. It is possible that infection by C. rodentium $\left(\lambda_{s t} x_{2 d a c t}\right)$ might trigger more overt microangiopathy and thus more closely resemble human HUS, in murine strains different from the C57BL/6 strain utilized here.

Given that a central goal of this study was to test whether C. roden-

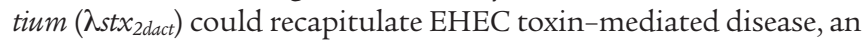
important finding was the requirement for Tir in promoting Stxmediated disease in this model. Colonization by a Tir-deficient derivative of $C$. rodentium ( $\lambda$ st $x_{2 \text { dact }}$ ) was many orders of magnitude lower than colonization by the parental strain. A Tir-encoding plasmid complemented the mutant for the ability to colonize mice and cause disease. The kinetics of colonization, weight loss, and death were somewhat slower than with C. rodentium $\left(\lambda s t x_{2 d a c t}\right)$, suggesting that, as observed in previous studies $(20,84)$, plasmid-based complementation of a Tir-deficient C. rodentium mutant may result in only partial restoration of the wild-type phenotype.

Interestingly, in spite of the reports that the Stx receptor $\mathrm{Gb}_{3}$ is expressed on cells in the distal colon of the mouse $(32,103)$, the streptomycin pretreatment and gnotobiotic mouse models of EHEC infection do not typically result in obvious intestinal damage (refs. 57, 59, and A. Melton-Celsa, unpublished observations). Mild inflammatory cell infiltration, goblet cell depletion, and intestinal epithelial necrosis have been reported in a few studies $(97,104-106)$. In contrast, we found here dramatic intestinal damage in mice infected with C. rodentium $\left(\lambda s t x_{2 \text { dact }}\right)$; indeed, these pathological changes were similar to those commonly observed in human infection by EHEC, which in some cases can mimic inflammatory bowel disease or ischemic colitis (107-110). It is tempting to speculate that $\mathrm{AE}$ lesion formation, a prominent feature of this murine infection model, is critical to facilitating Stx-mediated intestinal epithelial damage. The development of a murine model that encompasses both AE lesion formation and severe Stx-mediated tissue damage provides an opportunity to more fully explore the relationship between the pathogen-induced alteration in host cytoskeletal structure and subsequent local and systemic disease. 


\section{Methods}

Plasmids, bacterial strains, and growth conditions. Bacterial strains and plasmids used in this study are listed in Supplemental Tables 1 and 2. All bacteria were cultured in Luria-Bertani broth (LB) (Miller) at $37^{\circ} \mathrm{C}$, unless otherwise stated. Antibiotics were used at the following concentrations: kanamycin $(25 \mu \mathrm{g} / \mathrm{ml})$, zeocin $(75 \mu \mathrm{g} / \mathrm{ml})$, and chloramphenicol $(10 \mu \mathrm{g} / \mathrm{ml})$.

Sequencing of $\Phi 1720$ a-02 from Gobius EC1720. Sequencing of the newly identified $\Phi 1720$ a-02 from EC1720a, a strain originally isolated from retail ground beef (66) (provided by Kari Gobius, Food Science Australia, Tingalpa, Queensland, Australia) was performed using the panhandle PCR technique as previously described $(111,112)$. The adaptor sequences used were F-Adaptor 1 (Supplemental Table 3) and R-Adaptor 2 (Supplemental Table 3). Primers F-AP1 and R-AP2 (Supplemental Table 3) were used for the PCR reaction and sequencing of the PCR reaction, respectively. Reactions for restriction digests and ligation of adaptors to genomic $\Phi 1720 \mathrm{a}-02$ DNA were as follows: $1 \mu \mathrm{g}$ genomic $\Phi 1720 \mathrm{a}-02$ DNA, 10 pmol F-Adapter 1, 10 pmol R-Adapter 2, 10 U blunt-end restriction enzyme (EcoRV, PvuII, RsaI, SspI, XmnI, DraI, HincII, HpaI, ScaI), 2.5 U T4 DNA ligase, $2 \mu 1$ $20 \mathrm{mM}$ ATP, $4 \mu \mathrm{l}$ of $\times 10$ One-Phor-All buffer PLUS (Amersham), and up to $20 \mu \mathrm{l}$ water. Reactions were then incubated at $20^{\circ} \mathrm{C}$ for 16 hours. Next, enzymes were deactivated by heating at $68^{\circ} \mathrm{C}$ for 10 minutes, and reactions were ethanol-precipitated and resuspended in $50 \mu \mathrm{l}$ sterile water. The panhandle PCR reaction was then performed using $1 \mu \mathrm{l}$ of the ethanol precipitated template DNA, $2 \mu \mathrm{l}$ Taq $10 \times$ reaction buffer containing $20 \mathrm{mM}$ $\mathrm{MgCl}_{2}, 1 \mu \mathrm{l} 10 \mathrm{mM}$ dNTP mix, 10 pmol F-AP1 primer, 10 pmol gene-specific primer, $1 \mathrm{U}$ Taq polymerase, and up to $20 \mu \mathrm{l}$ water. The PCR cycle parameters were as follows: (a) $95^{\circ} \mathrm{C}$ for 1 minute, (b) $95^{\circ} \mathrm{C}$ for 30 seconds, (c) $68^{\circ} \mathrm{C}$ for 7 minutes; steps b and c were repeated 25 times. PCR reactions were then cleaned up using a QIAGEN spin kit and sequenced at the Tufts Core Sequencing Facility.

To confirm the nucleotide and protein sequences of StxA (Stx2d activatable A subunit) and StxB (Stx2d activatable B subunit) from the newly identified $\Phi 1720 a-02\left(\lambda_{s t x_{2 d a c t}}\right)$, fragments of both genes, the predicted promoter region, and the region upstream of stxA were amplified by PCR and TA cloned into JM109 high efficiency competent cells (Promega). The following primers (see Supplemental Table 3 for sequences) were used to clone each fragment: F-Oli218+R-Oli219 (593 bp), F-Oli224+R-Oli210 (1.490 kb), R-Oli220+F-Oli221 (1.647 kb), F-Oli222+R-Oli220 ( 2 kb), R-Oli223+F-Oli222 (1.159 kb), F-Oli224+R-Oli223 (1.3 kb), F-Oli221+ROli210 (918 bp), F-Oli224+R-Oli219 (1.2 kb), R-Oli219+F-Oli226 ( 2.1 kb), and F-Oli228+R-Oli219 ( 2 kb). The clones were screened by colony PCR and restriction digestion. Correct clones were sequenced at the Tufts Core Sequencing Facility. Fragments were aligned using BioEdit software (http://www.mbio.ncsu.edu/bioedit/bioedit.html) and/or MacVector. Nucleotide sequences of stxA (Stx2d activatable A subunit) and stxB (Stx2d activatable B subunit) were submitted to GenBank and were assigned the following accession numbers: JN194203 and JN194204.

Alignment of $\Phi 1720 a-02$ Stx $A$ and St $x B$ with other Stxs. The predicted amino acid sequence of the $A$ and B subunits of the $\Phi 1720 \mathrm{a}-02$ from C. rodentium $\left(\lambda s t x_{2 d a c t}\right)$ were aligned with the A and B subunits of Stx 2 from EDL933 (GenBank X078655), Stx2c from E32511 (GenBank M59432), Stx2d from EH250 (GenBank AF043627), Stx2dact (formerly called Stx2vhb) from B2F1 (GenBank AF479829), and Stx2e from S1191 (GenBank M21534). The sequences were aligned using the Align Plus 5 program, version 5.03 (Scientific \& Educational Software) following the global-ref alignment procedure (113) and the scoring matrix BLOSUM 62 (114).

Antibiotic marking of $\Phi 1720$-02. To create an antibiotic-marked Stx2expressing $\Phi 1720$ a-02 bacteriophage, a chloramphenicol resistance marker $\left(\right.$ cat, $\mathrm{Cm}^{\mathrm{R}}$ ) was inserted into the nonessential gene $R z(115)$ using lambda red recombination. Briefly, a 707-bp fragment containing sequence upstream of the $R z$ gene was amplified from EC1720a genomic DNA using primers F-425 and R-426, flanked by SphI and BamHI sites. A 692-bp fragment containing sequence downstream of the $R z$ gene was amplified by PCR using primers F-259 and R-427 with BamHI and SacI sites. A 900-bp cat cassette was then amplified from pBR328 with flanking BamHI sites using primers F-265 and R-266. A tertiary PCR reaction was done using the three PCR fragments with primers F-425 and R-427. This tertiary PCR fragment was then inserted between the SphI and SacI sites of pUC to create $\mathrm{pBJK5}$. This plasmid was digested with $\mathrm{SphI}$ and SacI to release a 2.3-kb fragment containing the cat cassette flanked by regions of the $R z$ gene. This fragment was electroporated into arabinose-induced EC1720a containing the lambda red recombinase plasmid pKD46. The culture was recovered in $1 \mathrm{ml} \mathrm{SOC}$ for 1.5 hours at $37^{\circ} \mathrm{C}$ and then plated on LB plates supplemented with chloramphenicol to select for recombinants. Recombinants were screened by PCR using primer pairs F-425/R-427 and F-265/R-266.

Creation of an stx deletion within EC1720a $\Delta R z:$ :cat. Chimeric PCR was used to produce a fragment containing the $\mathrm{Km}^{\mathrm{R}}$ cassette within an in-frame deletion of stx $A B$. Three PCR reactions were done as follows: (a) template pUC18K with primers $2 \mathrm{dH} 1 / 2 \mathrm{dH} 2$, (b) template EC1720a genomic DNA with primers F-498/R-2dH1AP, and (c) template EC1720a genomic DNA with primers F-2dH2AP and R-499. A tertiary PCR was then done using these three PCR reactions as templates, and the resulting PCR product was then electroporated into EC1720a $\Delta R z:: c a t$ containing the lambda red recombinase plasmid pKD46 and induced to recombine. Recombinants were selected on LB plates supplemented with chloramphenicol and kanamycin and then screened by PCR using the following primer pairs: F-498/R-499, F-2dH1/R-2dH2, F-316/R-2dH2, F-316/R-398, and F-2dH1/R-398. The loss of pKD46 from the resulting strain, EC1720a $\Delta s x_{2 d a c t} A B:: k a n \Delta R z:: c a t$, was confirmed by plating the strain on both kanamycin and ampicillin.

Isolation of $\Phi 1720 a \Delta R z:: c a t$ and $\Phi 1720 a \Delta s t x 2 d:: k a n \Delta R z:: c a t$. Recombinant Stx bacteriophages $\Phi 1720 \mathrm{a} \Delta R z:: c a t$ and $\Phi 1720 \mathrm{a} \Delta R z:: c a t \Delta s t x_{2 \text { dact }} A B:: k a n$ were isolated from the newly modified genetically manipulated EHEC strains JB-13-06 and JB-13-28 (Supplemental Table 1), respectively, as previously described $(66,70)$. Briefly, EHEC isolates were treated with mitomycin C $(0.5 \mu \mathrm{g} / \mathrm{ml})$ to induce the bacteriophage lytic cycle and production of phage. The cells were treated with $0.5 \mathrm{ml}$ chloroform per $3.0 \mathrm{ml}$ broth culture and were filtered through a $0.45-\mu \mathrm{m}$-pore-size filter to ensure a cell-free lysate.

Construction of C. rodentium $\left(\lambda_{s t x_{2 d a c t}}\right)$ and C. rodentium $\left(\lambda s t x_{2 d a c t}: * k a n^{R}\right)$. The genetically engineered Stx 2 dact bacteriophages $\Phi 1720 a-02 \Delta R z:: c a t$, which has a chloramphenicol resistance cassette inserted into $R z$, and $\Phi 1720 \mathrm{a}-02 \Delta R z:: c a t \Delta s t x 2 d:: k a n$, which has a chloramphenicol resistance cassette inserted into $R z$ and a kanamycin resistance cassette inserted into Stx2dactAB, were isolated from genetically modified STEC strains EC1720a $\Delta R z:: c a t$ and EC1720a $\Delta R z:: c a t \Delta s t x 2 d:: k a n$, respectively. C. rodentium DBS100 (11) was provided with cell surface receptor for bacteriophage Stx $2 \mathrm{~d}$ by transformation of plasmid pTROY9, which contains the E. coli $\operatorname{lamB}$ gene and a tetracycline resistance marker $(116,117)$. The lambda phage receptor was put into DBS100, creating DBS100/pTroy9, and induced by growing overnight at $37^{\circ} \mathrm{C}$ in lambda broth with $0.2 \%$ maltose and $10 \mathrm{mM} \mathrm{MgSO}_{4}$. This strain was then lysogenized with the antibioticmarked bacteriophages as described previously (118), resulting in DBS770 [C. rodentium $\left(\lambda_{\left.s t x_{2 d a c t}\right)}\right]$ or DBS771 [C. rodentium $\left(\lambda_{\left.s t x_{2 d a c t}: . k a n^{R}\right)}\right)$.

Generation of C. rodentium $\left(\lambda_{s t x_{2 d a c t}}\right) \Delta$ tir. The C. rodentium $\left(\lambda_{s t x_{2 d a c t}}\right)$ tir deletion mutant was made as previously described (119) using a slightly modified version of the 1-step PCR-based gene activation protocol (120).

Construction of a plasmid expressing C. rodentium Tir. Plasmid DNA was isolated using the QIAGEN Miniprep procedure. Oligonucleotides were from Invitrogen. The C. rodentium complementation vector, pEM129 (pTir), was created using a modified version of pMB46, pEM123, containing the additional unique restriction sites MluI and SacII between KpnI 
and HindIII. C. rodentium tir - cesT was then amplified using F-MluI-CrtirU and R-SacII-Cr-tirL and ligated into MluI and SacII site of PEM123 to create pEM129. Sequencing was performed at the DNA Sequencing Core Facility at Tufts Medical School.

ELISA quantification of Stx. Overnight bacterial cultures with antibiotic were diluted into a $5-\mathrm{ml}$ culture with new medium and antibiotic. The cultures were grown to an $\mathrm{OD}_{600}$ of $0.5-0.7$. Mitomycin C (5 $\left.\mu \mathrm{lof} 0.5 \mathrm{ng} / \mathrm{ml}\right)$ was added to cultures, and they were grown overnight with agitation. Cultures were spun at $17,800 \times g$ for 5 minutes at room temperature. Supernatants were collected for analysis. To prepare pellets for ELISA, pellets were washed with $1 \mathrm{M}$ Tris $\mathrm{pH} 8$ on ice, frozen at $-70^{\circ} \mathrm{C}$ for 30 minutes, resuspended in $1 \mathrm{ml}$ ice-cold $1 \mathrm{M}$ Tris $\mathrm{pH}$ 8, and sonicated (20-second bursts, 3 times) and prepared for Stx2 ELISAs. 96-well plates (Corning MaxiSorp) were coated with 4D1 Stx2 antibody (a gift from Cheleste Thorpe, Tufts University) at 1:1,000 in coating buffer, $\mathrm{pH} 9.6$, overnight at $4^{\circ} \mathrm{C}$. The plate was then blocked with $2 \%$ BSA in PBS or coating buffer for 1 hour at room temperature. Plates were washed 5 times with PBS/Tween 20 (0.05\%). Samples of bacterial supernatants or lysed pellets were added to wells, then incubated 1 hour at room temperature. The primary antibody, rabbit antiStx2 203 $\alpha$ CT69 (a gift from Cheleste Thorpe), was added to the wells for 30 minutes, followed by secondary antibody, anti-rabbit IgG Fc AP conjugate (Promega), for 30 minutes. Freshly prepared para-nitrophenyl phosphate (Sigma-Aldrich) was used as substrate. ODs were read at $405 \mathrm{~nm}$.

Mucus activation assays. Activation assays were performed as previously described $(46,58)$. Briefly, culture supernatants, were incubated with intestinal mucus from the small intestine of a mouse at a final concentration of $1 \mathrm{mg} / \mathrm{ml}$ for 2 hours at $37^{\circ} \mathrm{C}$. As a control, a separate sample of each preparation was treated with HEPES buffer and incubated in the same manner. Following incubation with mucus or HEPES, protease inhibitor was added and samples were frozen at $-20^{\circ} \mathrm{C}$ until ready to assay. The cytotoxicity of the samples was then determined on Vero cells (as described in refs. 46, 58). The level of activation was determined by dividing the cytotoxicity of the mucus-treated sample by the cytotoxicity of the HEPES-treated sample. Data shown are the average \pm SEM of at least 2 activation assays.

Analysis of pedestal formation by C. rodentium on cultured cells. Filamentous actin staining (FAS) assays using C. rodentium were done as previously described (119). Briefly, a single colony from each strain was grown in $1 \mathrm{ml}$ medium (with or without antibiotic) for 8 hours. Cultures were diluted 1:500 into $5 \mathrm{ml}$ DMEM supplemented with 0.1 M HEPES ( $\mathrm{pH} 7.0$ ) (with or without antibiotic) and incubated at $37^{\circ} \mathrm{C}$ without agitation with $5 \% \mathrm{CO}_{2}$ for $12-15$ hours. Cell monolayers were prepared by splitting $95 \%-100 \%$ confluent MEFs into 24-well culture plates containing sterile glass coverslips, followed by overnight growth at $37^{\circ} \mathrm{C}$ with $5 \% \mathrm{CO}_{2}$. Prior to seeding onto culture plates, MEFs were maintained in MEF cell culture medium (DMEM [high glucose] plus 10\% FBS with penicillin, streptomycin, and glutamine) at $37^{\circ} \mathrm{C}, 5 \% \mathrm{CO}_{2}$. For infections, cell monolayers were washed twice with sterile PBS, followed by addition of FAS medium containing $25 \mu$ lovernight-cultured C. rodentium to each well. Plates were spun at $700 \mathrm{~g}$ for 10 minutes, then incubated at $37^{\circ} \mathrm{C}$ with $5 \%$ $\mathrm{CO}_{2}$ for 3 hours. After 1.5 hours, plates were spun again at $700 \mathrm{~g}$ for an additional 10 minutes to insure proper bacterial binding to cells. After 3 hours, cells were washed twice with sterile PBS, and $0.5 \mathrm{ml}$ prewarmed FAS medium was added to each well, followed by an additional 3 hours incubation. Cells were washed 5 times with sterile PBS, fixed with 4\% PFA for 30 minutes, washed, permeabilized with $0.1 \%$ Triton X-100, and then stained with phalloidin (Molecular Probes, Invitrogen) (1:100) and DAPI (1:500). After cells were washed an additional 3 times with PBS, the coverslips were mounted on slides using ProLong Gold antifade reagent (Invitrogen).

Mouse infections. Mice were purchased from the Jackson Laboratory and housed in the University of Massachusetts Medical School (UMass) animal facility. Female 3- to 8-week old C57BL/6J mice were gavaged with PBS or approximately $5 \times 10^{9}$ of overnight culture of C. rodentium in $100 \mu \mathrm{lPBS}$, an inoculum that minimizes the potential variability in colonization kinetics (119). Inoculum concentrations were confirmed by serial dilution plating. C. rodentium fecal shedding was determined by serial dilution plating of fecal slurries (10\% w/v in PBS) on MacConkey agar with selection for kanamycin, chloramphenicol, or kanamycin and chloramphenicol, as appropriate. When complemented strains containing antibiotics were used, feces were plated on plates containing both antibiotics. Previously we tested the rate of plasmid loss by plating on only one antibiotic and determined that it was minimal. Fecal water content was evaluated as previously described (71). Water content in stool was expressed as the percentage of wet weight minus dry weight divided by wet weight. Fecal occult blood was assessed by Sure-Vue Fecal Occult Blood Test (Fisher Healthcare). Fecal occult scores were as follows: 0 , no occult blood; 0.5 , trace amounts of fecal occult blood; 1 , presence of fecal occult blood. Body weights were monitored daily, and mice were euthanized if they lost $>20 \%$ of their body weight. Some mice became moribund or died prior to the scheduled necropsy date, and these mice were necropsied early. Mouse urinalysis (for proteinuria and hematuria) was performed by collecting urine into a 1.5 - $\mathrm{ml}$ Eppendorf tube. The urine in the tube was thoroughly mixed, and a $5-\mu \mathrm{l}$ aliquot was pipetted onto a Chemstrip 4MD urinalysis test strip (Roche Diagnostics). After 60 seconds, the color change on the strip was compared to a supplied color scale. The range of protein measured was $0-500 \mathrm{mg} / \mathrm{dl}$, with 0 indicating undetectable protein, 0.5 indicating trace, 1.0 indicating approximately $30 \mathrm{mg} / \mathrm{dl}, 2.0$ indicating $\sim 100 \mathrm{mg} / \mathrm{dl}$, and 3.0 indicating $\sim 500 \mathrm{mg} / \mathrm{dl}$. The range of hematuria measured was $0-250$ erythrocytes/ $\mu l$, with the scale of 0 indicating undetectable hematuria, 10 indicating trace hematuria, 50 indicating $\sim 50$ erythrocytes $/ \mu l$, and 250 indicating $\sim 250$ erythrocytes $/ \mu$ l. The amount of Kim-1 in mouse urine was measured using a Kim-1 ELISA kit (Adipo Bioscience) according to manufacturer's protocols. All experimental groups contained at least 5 mice.

Tissue collection and histology. At necropsy, distal colon $(\sim 0.5 \mathrm{~cm})$ and one kidney were snap frozen in liquid nitrogen and stored at $-80^{\circ} \mathrm{C}$ until RNA or protein isolation. Remaining colon, cecum, longitudinally divided kidneys, spleen, heart, lung, liver, and nasal turbinates were fixed in $10 \%$ buffered formalin, dehydrated, and embedded in paraffin. Five-micrometer tissue sections were cut and stained with H\&E and/or PAS. For CCR1 staining of renal tissues by immunofluorescence, sections were stained with rabbit anti-mouse CCR1 primary antibody (ProSci Inc.) followed by staining with secondary goat anti-rabbit conjugated Alexa488 (Invitrogen). For immunohistochemistry, sections were stained with rabbit anti-mouse CCR1 primary antibody (ProSci Inc.) followed by the Envision+ Dual link system HRP (Dako). Tissue sections were evaluated and scored in a blinded manner.

Tissue protein isolation and cytokine analysis. Tissues were homogenized and protein was extracted using the Bio-Plex Cell Lysis Kit (Bio-Rad) following the manufacturer's instructions. Briefly, 200-500 $\mu \mathrm{l}$ lysis solution was added to sample. Sample was ground on ice using disposable Kontes tubes and disposable pestle and frozen at $-80^{\circ} \mathrm{C}$. Sample was then thawed and sonicated (duty cycle 40 , output 6 , pulse 18 times). Sample was then centrifuged at $4,500 \mathrm{~g}$ for 20 minutes at $4^{\circ} \mathrm{C}$. Protein concentration of the sample was determined by BCA assay (Thermo Scientific), and protein concentration was adjusted to $2 \mu \mathrm{g} / \mathrm{ml}$ with lysing solution. Cytokine analysis was performed by the UMass Mouse Phenotyping Core Facility using the cytokine mouse 23-plex Bio-Plex kit (Bio-Rad) and Bio-Plex 200 Luminex machine. For analysis of CCR1 by ELISA, kidneys were taken from mice between 3 and 7 days after infection, snap frozen, and stored at $-80^{\circ} \mathrm{C}$ until further processing. Kidneys were then thawed on ice, resuspended in PBS, homogenized using a Tissuemiser (Fisher Scientific), and centrifuged at $4^{\circ} \mathrm{C}$. The supernatant was assayed via ELISA (Chemokine C-C-Motif Receptor 1 [CCR1] ELISA, Antibodies-Online.com) according to the manufacturer's protocols. 
Bb, sC5b-9, C3, and D-dimer ELISAs. For Bb, sC5b-9, and C3 analyses, blood was drawn via cardiac bleed at 6-8 days after infection from mock-infected mice or mice infected with the designated C. rodentium strain. Blood was allowed to clot for 30 minutes at room temperature and was then spun at $10,000 \mathrm{~g}$ for 15 minutes at $4^{\circ} \mathrm{C}$, and serum was collected. Serum was spun at $10,000 \mathrm{~g}$ for an additional 15 minutes at $4^{\circ} \mathrm{C}$, and the remaining serum was collected and frozen at $-80^{\circ} \mathrm{C}$ until analysis. Mouse factor $\mathrm{B}$ (BF, Bb) ELISA Kit (TSZ ELISA) was used according to the manufacturer's protocols to measure serum $\mathrm{Bb}$. Mouse sC5b-9 was measured using the mouse terminal complement complex C5b-9 (TCC C5b-9) ELISA Kit (TSZ ELISA) according to manufacturer's protocols. Concentrations of serum C3 were determined using a Mouse C3 ELISA Kit (GenWay) according to the manufacturer's protocols. To measure levels of D-dimer in the blood, whole blood was taken from mice via cardiac bleed at 4 time points based on colonization level (1: $10^{7} \mathrm{CFU} / \mathrm{g}$ feces; $2: 10^{8} \mathrm{CFU} / \mathrm{g}$ feces; $3: 10^{9} \mathrm{CFU} / \mathrm{g}$ feces; and 4: prior to euthanasia [after a mouse had lost $>15 \%$ body weight]) and collected into a tube containing trisodium citrate anticoagulant (at a concentration of 9:1 blood/anticoagulant). Blood was centrifuged for 10 minutes at $2,500 \mathrm{~g}$, and plasma was isolated and stored at $-20^{\circ} \mathrm{C}$ until analysis. ELISA was performed using a Mouse D-Dimer (D2D) ELISA kit (K-Assay, Kamiya Biomedical Co.).

Serum chemistry and cytokine analysis. Blood was collected via cardiac puncture at necropsy and allowed to clot on ice for 30 minutes. Blood was spun at $10,000 \mathrm{~g}$ for 15 minutes at $4^{\circ} \mathrm{C}$, and serum was collected. Serum was spun at $10,000 \mathrm{~g}$ for an additional 15 minutes at $4^{\circ} \mathrm{C}$, and the remaining serum was collected and frozen at $-80^{\circ} \mathrm{C}$ until analysis. The UMass Mouse Phenotyping Core Facility determined serum BUN and creatinine using a Cobas analyzer and serum cytokine concentrations using a mouse 23-plex Bio-plex kit (Bio-Rad) with a Bioplex 200 Luminex analyzer. Additional serum chemistry tests including the comprehensive metabolic profile (i.e., electrolytes, creatinine, BUN, AST, globulin, ALT, total protein, alkaline phosphatase, $\mathrm{CPK}$, and albumin) were performed at IDEXX laboratories (North Grafton).

Complete blood cell count analysis. For complete blood count and hematological analysis, at 3-7 days after infection $500 \mu \mathrm{l}$ murine whole blood was collected by cardiac puncture into an EDTA-containing Eppendorf tube and mixed thoroughly. Tests were performed at the UMass Animal Facility Laboratory and at IDEXX Laboratories. Red blood cell and platelet counts were also measured daily for up to 10 days after infection by flow cytometry in mock-infected mice and mice infected with C. rodentium $\left(\lambda_{s t x_{2 d a c t}}\right)$ as previously described $(121,122)$.

TEM. Mouse intestinal tissue samples were taken at various time points after infection and fixed in $2.5 \%$ gluteraldehyde in $0.05 \mathrm{M}$ sodium phosphate buffer, $\mathrm{pH}$ 7.2. Samples were processed and analyzed at the UMass Electron Microscopy core facility according to standard procedures. Briefly, fixed samples were moved into fresh $2.5 \%$ gluteraldehyde in $0.05 \mathrm{M}$ sodium phosphate buffer and left overnight at $4^{\circ} \mathrm{C}$. The sam- ples were then rinsed twice in the same fixation buffer and post-fixed with $1 \%$ osmium tetroxide for 1 hour at room temperature. Samples were then washed twice with $\mathrm{DH}_{2} \mathrm{O}$ for 20 minutes at $4{ }^{\circ} \mathrm{C}$ and then dehydrated through a graded ethanol series of $20 \%$ increments, before 2 changes in $100 \%$ ethanol. Subsequently, samples were infiltrated first with 2 changes of $100 \%$ propylene oxide and then with a 1:1 mix of propylene oxide/SPI-Pon 812 resin. The following day, 3 changes of fresh $100 \%$ SPI-Pon 812 resin were done before the samples were polymerized at $68^{\circ} \mathrm{C}$ in plastic capsules. The samples were then reoriented, and thin sections were placed on copper support grids and stained with lead citrate and uranyl acetate. Sections were examined using the FEI Tecani $12 \mathrm{BT}$ with $80-\mathrm{kV}$ accelerating voltage, and images were captured using a Gatan TEM CCD camera.

Statistics. Data were analyzed using GraphPad Prism software. Comparison of multiple groups was performed using 1-way ANOVA with Tukey's multiple comparison post-tests or 2-way ANOVA with Bonferroni's posttests. Statistical significance of differences between 2 groups was evaluated using 2 -tailed unpaired $t$ tests. In all tests, $P$ values below 0.05 were considered statistically significant. In all graphs, data represent the mean \pm SEM, unless otherwise indicated.

Nucleotide sequence and accession numbers. stxA (Stx2d activatable A subunit) from Phage 1720a02: BankIt1463613 Seq1 JN194203. stxB (Stx2d activatable B subunit) from Phage 1720a02: BankIt1463613 Seq2 JN194204.

Study approval. All animal studies were approved by the UMass Department of Animal Medicine and IACUC (protocol 2049).

\section{Acknowledgments}

We thank the UMass Diabetes and Endocrinology Research Center facility for fixing, sectioning, and staining all tissue sections and particularly Lara Strittmatter and Gregory Hendricks of the UMass Electron Microscopy Core Facility for the invaluable electron microscopy work. The UMass Mouse Phenotyping Core Facility performed Luminex cytokine and blood chemistry studies. This work was supported by NIH R21 AI92009 and R01 AI46454 to J.M. Leong; R37 AI20148 to A. O’Brien; R01 049842, R01 AI049842, and 026731 PHS P01CA026731 to D.B. Schauer; and NIH/New England Regional Center for Excellence, Biodefense and Emerging Infectious Diseases Cooperative Pilot Projects Program R01 DK59101 to J.R. Butterton and D.B. Schauer.

Received for publication January 5, 2012, and accepted in revised form August 9, 2012.

Address correspondence to: John M. Leong, Department of Molecular Biology and Microbiology, Tufts University School of Medicine, 136 Harrison Avenue, Boston, Massachusetts 02111, USA. Phone: 617.636.0488; Fax: 617.636.0337; E-mail: john.leong@tufts.edu.
1. Bielaszewska M, et al. Characterisation of the Escherichia coli strain associated with an outbreak of haemolytic uraemic syndrome in Germany, 2011: a microbiological study. Lancet Infect Dis. 2011; 11(9):671-676

2. Kaper JB, Nataro JP, Mobley HL. Pathogenic Escherichia coli. Nat Rev Microbiol. 2004;2(2):123-140.

3. Pennington $\mathrm{H}$. Escherichia coli O157. Lancet. 2010; 376(9750):1428-1435.

4. Amirlak I, Amirlak B. Haemolytic uraemic syndrome: an overview. Nephrology. 2006;11(3):213-218.

5. Karmali MA, Gannon V, Sargeant JM. Verocytotoxin-producing Escherichia coli (VTEC). Vet Microbiol. 2009; 140(3-4):360-370.

6. Tarr PI, Gordon CA, Chandler WL. Shiga-toxinproducing Escherichia coli and haemolytic urae- mic syndrome. Lancet. 2005;365(9464):1073-1086.

7. Karch H, Tarr PI, Bielaszewska M. Enterohaemorrhagic Escherichia coli in human medicine. Int J Med Microbiol. 2005;295(6-7):405-418.

8. Scheiring J, Rosales A, Zimmerhackl LB. Clinical practice. Today's understanding of the haemolytic uraemic syndrome. Eur J Pediatr. 2010;169(1):7-13.

9. Scheiring J, Andreoli SP, Zimmerhackl LB. Treatment and outcome of Shiga-toxin-associated hemolytic uremic syndrome (HUS). Pediatr Nephrol. 2008;23(10):1749-1760

10. Mead PS, Griffin PM. Escherichia coli O157:H7. Lancet. 1998;352(9135):1207-1212.

11. Schauer DB, Falkow S. Attaching and effacing locus of a Citrobacter freundii biotype that causes transmissible murine colonic hyperplasia. Infect
Immun. 1993;61(6):2486-2492.

12. Moon HW, Whipp SC, Argenzio RA, Levine MM, Giannella RA. Attaching and effacing activities of rabbit and human enteropathogenic Escherichia coli in pig and rabbit intestines. Infect Immun. 1983; 41(3):1340-1351.

13. Kenny B, Finlay BB. Protein secretion by enteropathogenic Escherichia coli is essential for transducing signals to epithelial cells. Proc Natl Acad Sci US A. 1995;92(17):7991-7995.

14. McDaniel TK, Jarvis KG, Donnenberg MS, Kaper JB. A genetic locus of enterocyte effacement conserved among diverse enterobacterial pathogens. Proc Natl Acad Sci U S A. 1995;92(5):1664-1668.

15. Donnenberg MS, Kaper JB. Construction of an eae deletion mutant of enteropathogenic Escherichia 
coli by using a positive-selection suicide vector Infect Immun. 1991;59(12):4310-4317.

16. Jerse AE, Yu J, Tall BD, Kaper JB. A genetic locus of enteropathogenic Escherichia coli necessary for the production of attaching and effacing lesions on tissue culture cells. Proc Natl Acad Sci U S A. 1990; 87(20):7839-7843

17. de Grado M, Abe A, Gauthier A, Steele-Mortimer $\mathrm{O}, \mathrm{DeVinney} \mathrm{R}$, Finlay BB. Identification of the intimin-binding domain of Tir of enteropathogenic Escherichia coli. Cell Microbiol. 1999;1(1):7-17.

18. Kenny B, Ellis S, Leard AD, Warawa J, Mellor H, Jepson MA. Co-ordinate regulation of distinct host cell signalling pathways by multifunctional enteropathogenic Escherichia coli effector molecules. Mol Microbiol. 2002;44(4):1095-1107.

19. Hartland EL, et al. Binding of intimin from enteropathogenic Escherichia coli to Tir and to host cells. Mol Microbiol. 1999;32(1):151-158.

20. Deng W, Vallance BA, Li Y, Puente JL, Finlay BB. Citrobacter rodentium translocated intimin receptor (Tir) is an essential virulence factor needed for actin condensation, intestinal colonization and colonic hyperplasia in mice. Mol Microbiol. 2003; 48(1):95-115.

21. Ritchie JM, Thorpe CM, Rogers AB, Waldor MK Critical roles for stx2, eae, and tir in enterohemorrhagic Escherichia coli-induced diarrhea and intestinal inflammation in infant rabbits. Infect Immun. 2003;71(12):7129-7139.

22. Schauer DB, Falkow S. The eae gene of Citrobacter freundii biotype 4280 is necessary for colonization in transmissible murine colonic hyperplasia. Infect Immun. 1993;61(11):4654-4661.

23. Tzipori S, Gunzer F, Donnenberg MS, de Montigny L, Kaper JB, Donohue-Rolfe A. The role of the eaeA gene in diarrhea and neurological complications in a gnotobiotic piglet model of enterohemorrhagic Escherichia coli infection. Infect Immun. 1995; 63(9):3621-3627.

24. Donnenberg MS, Tzipori S, McKee ML, O’Brien AD, Alroy J, Kaper JB. The role of the eae gene of enterohemorrhagic Escherichia coli in intimate attachment in vitro and in a porcine model. J Clin Invest. 1993;92(3):1418-1424.

25. Marches $\mathrm{O}$, et al. Role of Tir and intimin in the virulence of rabbit enteropathogenic Escherichia coli serotype O103:H2. Infect Immun. 2000; 68(4):2171-2182

26. O'Brien AD, et al. Shiga toxin: biochemistry, genetics, mode of action, and role in pathogenesis. Curr Top Microbiol Immunol. 1992;180:65-94.

27. Schuller S, Frankel G, Phillips AD. Interaction of Shiga toxin from Escherichia coli with human intestinal epithelial cell lines and explants: Stx2 induces epithelial damage in organ culture. Cell Microbiol. 2004;6(3):289-301.

28. Muhldorfer I, et al. Regulation of the Shiga-like toxin II operon in Escherichia coli. Infect Immun. 1996;64(2):495-502.

29. Waldor MK, Friedman DI. Phage regulatory circuits and virulence gene expression. Curr Opin Microbiol. 2005;8(4):459-465.

30. Schmidt H. Shiga-toxin-converting bacteriophages. Res Microbiol. 2001;152(8):687-695.

31. Obrig TG. Escherichia coli shiga toxin mechanisms of action in renal disease. Toxins (Basel). 2010; 2(12):2769-2794

32. Schuller S. Shiga toxin interaction with human intestinal epithelium. Toxins. 2011;3(6):626-639.

33. Sandvig K, van Deurs B. Endocytosis, intracellular transport, and cytotoxic action of Shiga toxin and ricin. Physiol Rev. 1996;76(4):949-966.

34. O'Loughlin EV, Robins-Browne RM. Effect of Shiga toxin and Shiga-like toxins on eukaryotic cells. Microbes Infect. 2001;3(6):493-507.

35. Tesh VL, Ramegowda B, Samuel JE. Purified Shigalike toxins induce expression of proinflammatory cytokines from murine peritoneal macrophages. Infect Immun. 1994;62(11):5085-5094.

36. Sandvig K. Shiga toxins. Toxicon. 2001; 39(11):1629-1635.

37. Thorpe CM, Smith WE, Hurley BP, Acheson DW. Shiga toxins induce, superinduce, and stabilize a variety of $\mathrm{C}-\mathrm{X}-\mathrm{C}$ chemokine mRNAs in intestinal epithelial cells, resulting in increased chemokine expression. Infect Immun. 2001;69(10):6140-6147.

38. Nakao H, Takeda T. Escherichia coli Shiga toxin. J Nat Toxins. 2000;9(3):299-313.

39. Melton-Celsa A, Mohawk K, Teel L, O'Brien A. Pathogenesis of Shiga-toxin producing escherichia coli. Curr Top Microbiol Immunol. 2012;357:67-103.

40. Ostroff SM, Tarr PI, Neill MA, Lewis JH, HargrettBean N, Kobayashi JM. Toxin genotypes and plasmid profiles as determinants of systemic sequelae in Escherichia coli O157:H7 infections. J Infect Dis. 1989;160(6):994-998.

41. Croxen MA, Finlay BB. Molecular mechanisms of Escherichia coli pathogenicity. Nat Rev Microbiol. 2010;8(1):26-38.

42. Persson S, Olsen KE, Ethelberg S, Scheutz F. Subtyping method for Escherichia coli shiga toxin (verocytotoxin) 2 variants and correlations to clinical manifestations. J Clin Microbiol. 2007; 45(6):2020-2024

43. Eklund M, Leino K, Siitonen A. Clinical Escherichia coli strains carrying stx genes: stx variants and stx-positive virulence profiles. J Clin Microbiol. 2002;40(12):4585-4593.

44. Friedrich AW, et al. Escherichia coli harboring Shiga toxin 2 gene variants: frequency and association with clinical symptoms. J Infect Dis. 2002; 185(1):74-84

45. Ito $\mathrm{H}$, Terai $\mathrm{A}$, Kurazono $\mathrm{H}$, Takeda $\mathrm{Y}$, Nishibuchi $\mathrm{M}$. Cloning and nucleotide sequencing of Vero toxin 2 variant genes from Escherichia coli O91:H21 isolated from a patient with the hemolytic uremic syndrome. Microb Pathog. 1990;8(1):47-60.

46. Melton-Celsa AR, Kokai-Kun JF, O’Brien AD. Activation of Shiga toxin type $2 \mathrm{~d}(\mathrm{Stx} 2 \mathrm{~d})$ by elastase involves cleavage of the $\mathrm{C}$-terminal two amino acids of the $\mathrm{A} 2$ peptide in the context of the appropriate B pentamer. Mol Microbiol. 2002;43(1):207-215

47. Sauter KA, Melton-Celsa AR, Larkin K, Troxell ML, O'Brien AD, Magun BE. Mouse model of hemolytic-uremic syndrome caused by endotoxin-free Shiga toxin 2 (Stx2) and protection from lethal outcome by anti-Stx 2 antibody. Infect Immun. 2008; 76(10):4469-4478.

48. Keepers TR, Psotka MA, Gross LK, Obrig TG. A murine model of HUS: Shiga toxin with lipopolysaccharide mimics the renal damage and physiologic response of human disease. J Am Soc Nephrol. 2006; 17(12):3404-3414

49. Psotka MA, et al. Shiga toxin 2 targets the murine renal collecting duct epithelium. Infect Immun. 2009; 77(3):959-969.

50. Keepers TR, Gross LK, Obrig TG. Monocyte chemoattractant protein 1, macrophage inflammatory protein 1 alpha, and RANTES recruit macrophages to the kidney in a mouse model of hemolytic-uremic syndrome. Infect Immun. 2007; 75(3):1229-1236

51. Garcia A, et al. A naturally occurring rabbit model of enterohemorrhagic Escherichia coli-induced disease. J Infect Dis. 2002;186(11):1682-1686.

52. Garcia A, et al. Renal injury is a consistent finding in Dutch Belted rabbits experimentally infected with enterohemorrhagic Escherichia coli. J Infect Dis. 2006;193(8):1125-1134

53. Panda A, et al. Escherichia coli O157:H7 infection in Dutch belted and New Zealand white rabbits. Comp Med. 2010;60(1):31-37.

54. Mohawk KL, O’Brien AD. Mouse models of Escherichia coli O157:H7 infection and shiga toxin injection. J Biomed Biotechnol. 2011;2011:258185.
55. Mohawk KL, Melton-Celsa AR, Zangari T, Carroll EE, O'Brien AD. Pathogenesis of Escherichia coli O157:H7 strain 86-24 following oral infection of $\mathrm{BALB} / \mathrm{c}$ mice with an intact commensal flora. Microb Pathog. 2010;48(3-4):131-142.

56. Mohawk KL, Melton-Celsa AR, Robinson CM, O'Brien AD. Neutralizing antibodies to Shiga toxin type 2 (Stx2) reduce colonization of mice by Stx2expressing Escherichia coli O157:H7. Vaccine. 2010; 28(30):4777-4785.

57. Eaton KA, et al. Pathogenesis of renal disease due to enterohemorrhagic Escherichia coli in germ-free mice. Infect Immun. 2008;76(7):3054-3063.

58. Melton-Celsa AR, Darnell SC, O'Brien AD. Activation of Shiga-like toxins by mouse and human intestinal mucus correlates with virulence of enterohemorrhagic Escherichia coli O91:H21 isolates in orally infected, streptomycin-treated mice. Infect Immun. 1996;64(5):1569-1576.

59. Lindgren SW, Melton AR, O'Brien AD. Virulence of enterohemorrhagic Escherichia coli O91:H21 clinical isolates in an orally infected mouse model. Infect Immun. 1993;61(9):3832-3842.

60. Wadolkowski EA, Burris JA, O'Brien AD. Mouse model for colonization and disease caused by enterohemorrhagic Escherichia coli O157:H7. Infect Immun. 1990;58(8):2438-2445.

61. Wadolkowski EA, Sung LM, Burris JA, Samuel JE, O'Brien AD. Acute renal tubular necrosis and death of mice orally infected with Escherichia coli strains that produce Shiga-like toxin type II. Infect Immun. 1990;58(12):3959-3965

62. Barthold SW, Coleman GL, Jacoby RO, Livestone EM, Jonas AM. Transmissible murine colonic hyperplasia. Vet Pathol. 1978;15(2):223-236.

63. Luperchio SA, Schauer DB. Molecular pathogenesis of Citrobacter rodentium and transmissible murine colonic hyperplasia. Microbes Infect. 2001; 3(4):333-340

64. Mundy R, MacDonald TT, Dougan G, Frankel G, Wiles S. Citrobacter rodentium of mice and man. Cell Microbiol. 2005;7(12):1697-1706.

65. Borenshtein D, McBee ME, Schauer DB. Utility of the Citrobacter rodentium infection model in laboratory mice. Curr Opin Gastroenterol. 2008; 24(1):32-37.

66. Gobius KS, Higgs GM, Desmarchelier PM. Presence of activatable Shiga toxin genotype (stx2d) in Shiga toxigenic Escherichia coli from livestock sources. J Clin Microbiol. 2003;41(8):3777-3783.

67. Riley LW, et al. Hemorrhagic colitis associated with a rare Escherichia coli serotype. N Engl J Med. 1983; 308(12):681-685

68. Campellone KG, Giese A, Tipper DJ, Leong JM. A tyrosine-phosphorylated 12-amino-acid sequence of enteropathogenic Escherichia coli Tir binds the host adaptor protein Nck and is required for Nck localization to actin pedestals. Mol Microbiol. 2002; 43(5):1227-1241.

69. Pierard D, Muyldermans G, Moriau L, Stevens D, Lauwers S. Identification of new verocytotoxin type 2 variant B-subunit genes in human and animal Escherichia coli isolates. J Clin Microbiol. 1998; 36(11):3317-3322.

70. Teel LD, Melton-Celsa AR, Schmitt CK, O’Brien $\mathrm{AD}$. One of two copies of the gene for the activatable shiga toxin type 2d in Escherichia coli O91:H21 strain B2F1 is associated with an inducible bacteriophage. Infect Immun. 2002;70(8):4282-4291.

71. Borenshtein D, et al. Decreased expression of colonic Slc26a3 and carbonic anhydrase iv as a cause of fatal infectious diarrhea in mice. Infect Immun. 2009;77(9):3639-3650.

72. McBee ME, Zheng PZ, Rogers AB, Fox JG, Schauer DB. Modulation of acute diarrheal illness by persistent bacterial infection. Infect Immun. 2008; 76(11):4851-4858.

73. Morigi M, et al. Alternative pathway activation of 
complement by Shiga toxin promotes exuberant C3a formation that triggers microvascular thrombosis. J Immunol. 2011;187(1):172-180.

74. Orth D, Wurzner R. Complement in typical hemolytic uremic syndrome. Semin Thromb Hemost. 2010; 36(6):620-624.

75. Stahl AL, Sartz L, Karpman D. Complement activation on platelet-leukocyte complexes and microparticles in enterohemorrhagic Escherichia coli-induced hemolytic uremic syndrome. Blood. 2011;117(20):5503-5513.

76. Rovin BH, Phan LT. Chemotactic factors and renal inflammation. Am J Kidney Dis. 1998 ; 31(6):1065-1084.

77. Ray PE, Liu XH. Pathogenesis of Shiga toxininduced hemolytic uremic syndrome. Pediatr Nephrol. 2001;16(10):823-839.

78. Proulx F, Seidman EG, Karpman D. Pathogenesis of Shiga toxin-associated hemolytic uremic syndrome. Pediatr Res. 2001;50(2):163-171.

79. Rutjes NW, Binnington BA, Smith CR, Maloney MD, Lingwood CA. Differential tissue targeting and pathogenesis of verotoxins 1 and 2 in the mouse animal model. Kidney Int. 2002;62(3):832-845.

80. Ramos MV, et al. Chemokine receptor CCR1 disruption limits renal damage in a murine model of hemolytic uremic syndrome. Am J Pathol. 2012; 180(3):1040-1048.

81. Urbschat A, Obermuller N, Haferkamp A. Biomarkers of kidney injury. Biomarkers. 2011; 16(suppl 1):S22-S30.

82. Goldstein SL. Acute kidney injury biomarkers: renal angina and the need for a renal troponin I. BMC Med. 2011;9:135.

83. Han WK, Bailly V, Abichandani R, Thadhani R, Bonventre JV. Kidney Injury Molecule-1 (KIM-1): a novel biomarker for human renal proximal tubule injury. Kidney Int. 2002;62(1):237-244.

84. Mundy R, et al. Identification of a novel Citrobacter rodentium type III secreted protein, EspI, and roles of this and other secreted proteins in infection. Infect Immun. 2004;72(4):2288-2302.

85. Ritchie JM, Waldor MK. The locus of enterocyte effacement-encoded effector proteins all promote enterohemorrhagic Escherichia coli pathogenicity in infant rabbits. Infect Immun. 2005;73(3):1466-1474.

86. Caprioli J, Peng L, Remuzzi G. The hemolytic uremic syndromes. Curr Opin Crit Care. 2005; 11(5):487-492.

87. Litalien $\mathrm{C}$, et al. Circulating inflammatory cytokine levels in hemolytic uremic syndrome. Pediatr Nephrol. 1999;13(9):840-845.

88. Petruzziello-Pellegrini TN, et al. The CXCR4/ CXCR7/SDF-1 pathway contributes to the pathogenesis of Shiga toxin-associated hemolytic uremic syndrome in humans and mice. J Clin Invest. 2012; 122(2):759-776.

89. Simon M, Cleary TG, Hernandez JD, Abboud HE Shiga toxin 1 elicits diverse biologic responses in mesangial cells. Kidney Int. 1998;54(4):1117-1127.

90. van Setten PA, et al. Effects of TNF alpha on verocytotoxin cytotoxicity in purified human glomerular microvascular endothelial cells. Kidney Int. 1997; 51(4):1245-1256

91. van de Kar NC, Monnens LA, Karmali MA van Hinsbergh VW. Tumor necrosis factor and interleukin-1 induce expression of the verocytotoxin receptor globotriaosylceramide on human endothelial cells: implications for the pathogenesis of the hemolytic uremic syndrome. Blood. 1992; 80(11):2755-2764.

92. Foster GH, Armstrong CS, Sakiri R, Tesh VL. Shiga toxin-induced tumor necrosis factor alpha expression: requirement for toxin enzymatic activity and monocyte protein kinase $\mathrm{C}$ and protein tyrosine kinases. Infect Immun. 2000;68(9):5183-5189.

93. van Setten PA, Monnens LA, Verstraten RG, van den Heuvel LP, van Hinsbergh VW. Effects of verocytotoxin-1 on nonadherent human monocytes: binding characteristics, protein synthesis, and induction of cytokine release. Blood. 1996; 88(1):174-183

94. van Setten PA, et al. Monocyte chemoattractant protein-1 and interleukin- 8 levels in urine and serum of patents with hemolytic uremic syndrome. Pediatr Res. 1998;43(6):759-767.

95. Richardson SE, Karmali MA, Becker LE, Smith CR. The histopathology of the hemolytic uremic syndrome associated with verocytotoxin-producing Escherichia coli infections. Hum Pathol. 1988; 19(9):1102-1108

96. Star RA. Treatment of acute renal failure. Kidney Int. 1998;54(6):1817-1831.

97. Kurioka T, Yunou Y, Kita E. Enhancement of susceptibility to Shiga toxin-producing Escherichia coli O157:H7 by protein calorie malnutrition in mice. Infect Immun. 1998;66(4):1726-1734.

98. Fujii J, et al. Direct evidence of neuron impairment by oral infection with verotoxin-producing Escherichia coli $\mathrm{O} 157: \mathrm{H}$ - in mitomycin-treated mice. Infect Immun. 1994;62(8):3447-3453.

99. Karpman D, Connell H, Svensson M, Scheutz F, Alm P, Svanborg C. The role of lipopolysaccharide and Shiga-like toxin in a mouse model of Escherichia coli O157:H7 infection. J Infect Dis. 1997; 175(3):611-620.

100. Roche JK, Keepers TR, Gross LK, Seaner RM, Obrig TG. CXCL1/KC and CXCL2/MIP-2 are critical effectors and potential targets for therapy of Escherichia coli O157:H7-associated renal inflammation. Am J Pathol. 2007;170(2):526-537.

101. Motto DG, et al. Shigatoxin triggers thrombotic thrombocytopenic purpura in genetically susceptible ADAMTS13-deficient mice. J Clin Invest. 2005; 115(10):2752-2761.

102. Bull BS, Rubenberg ML, Dacie JV, Brain MC. Redblood-cell fragmentation in microangiopathic haemolytic anaemia: in vitro studies. Lancet. 1967; 2(7526):1123-1125

103.Imai Y, et al. Restricted expression of shiga toxin binding sites on mucosal epithelium of mouse distal colon. Infect Immun. 2003;71(2):985-990.

104. Taguchi H, et al. Experimental infection of germfree mice with hyper-toxigenic enterohaemorrhagic
Escherichia coli O157:H7, strain 6. J Med Microbiol. 2002;51(4):336-343.

105. Isogai E, et al. Role of tumor necrosis factor alpha in gnotobiotic mice infected with an Escherichia coli O157:H7 strain. Infect Immun. 1998;66(1):197-202.

106. Shimizu K, et al. Development of a lethal Shiga toxin-producing Escherichia coli infection mouse model using multiple mitomycin $\mathrm{C}$ treatment. Microb Pathog. 2003;35(1):1-9.

107. Moon HW. Comparative histopathology of intestinal infections. Adv Exp Med Biol. 1997;412:1-19.

108. Siegler RL. Spectrum of extrarenal involvement in postdiarrheal hemolytic-uremic syndrome.J Pediatr. 1994;125(4):511-518.

109.Sebbag H, Lemelle JL, Moller C, Schmitt M. Colonic stenosis after hemolytic-uremic syndrome. EurJ Pediatr Surg. 1999;9(2):119-120.

110.Griffin PM, et al. Illnesses associated with Escherichia coli O157:H7 infections. A broad clinical spectrum. Ann Intern Med. 1988;109(9):705-712.

111.Jones DH, Winistorfer SC. Genome walking with 2- to 4-kb steps using panhandle PCR. PCR Methods Appl. 1993;2(3):197-203.

112. Siebert PD, Chenchik A, Kellogg DE, Lukyanov KA, Lukyanov SA. An improved PCR method for walking in uncloned genomic DNA. Nucleic Acids Res. 1995; 23(6):1087-1088

113. Myers EW, Miller W. Optimal alignments in linear space. Comput Appl Biosci. 1988;4(1):11-17.

114. Henikoff S, Henikoff JG. Amino acid substitution matrices from protein blocks. Proc Natl Acad SciUS A. 1992;89(22):10915-10919.

115. Hernandez VJ, Edlind TD, Young RF, Ihler GM. The DNA between $\mathrm{Rz}$ and cosR in bacteriophage lambda is nonessential. Gene. 1985;33(3):363-365.

116. Wehmeier U, Sprenger GA, Lengeler JW. The use of lambda plac-Mu hybrid phages in Klebsiella pneumoniae and the isolation of stable Hfr strains. Mol Gen Genet. 1989;215(3):529-536.

117. de Vries GE, Raymond CK, Ludwig RA. Extension of bacteriophage lambda host range: selection, cloning, and characterization of a constitutive lambda receptor gene. Proc Natl Acad Sci US A. 1984; 81(19):6080-6084.

118.McDonough MA, Butterton JR. Spontaneous tandem amplification and deletion of the shiga toxin operon in Shigella dysenteriae 1. Mol Microbiol. 1999; 34(5):1058-1069.

119. Mallick EM, et al. Allele- and Tir-independent functions of intimin in diverse animal infection models. Front Microbiol. 2012;3:11.

120.Datsenko KA, Wanner BL. One-step inactivation of chromosomal genes in Escherichia coli K-12 using PCR products. Proc Natl Acad Sci U S A. 2000; 97(12):6640-6645.

121.Alugupalli KR, Michelson AD, Barnard MR, Leong JM. Serial determinations of platelet counts in mice by flow cytometry. Thromb Haemost. 2001; 86(2):668-671.

122.Alugupalli KR, et al. Spirochete-platelet attachment and thrombocytopenia in murine relapsing fever borreliosis. Blood. 2003;102(8):2843-2850. 